\title{
Superabsorbent aerogels from cellulose nanofibril hydrogels
}

\author{
Ossi Laitinen $^{\mathrm{a}, *}$, Terhi Suopajärvi ${ }^{\mathrm{b}}$, Juho Antti Sirviöc ${ }^{\mathrm{c}}$ and Henrikki Liimatainen ${ }^{\mathrm{d}}$
}

a, ${ }^{*}$ Ossi Laitinen, Postdoctoral Research Fellow, University of Oulu, Fibre and Particle Engineering, P.O. Box 4300, FI-90014 Oulu, Finland

b Terhi Suopajärvi, Postdoctoral Research Fellow, University of Oulu, Fibre and Particle Engineering, P.O. Box 4300, FI-90014 Oulu, Finland

c Juho Antti Sirviö, Adjunct Professor, University of Oulu, Fibre and Particle Engineering, P.O. Box 4300, FI-90014 Oulu, Finland

d Henrikki Liimatainen, Associate Professor, University of Oulu, Fibre and Particle Engineering, P.O. Box 4300, FI-90014 Oulu, Finland

*E-mail: ossi.laitinen@oulu.fi

\begin{abstract}
Deep eutectic solvents (DESs) are promising green chemicals that can function as solvents, reagents, and catalysts in many applications because of their biodegradability, ready availability, and low toxicity. Here, a DES of choline chloride-urea was used as a nonhydrolytic pretreatment medium to obtain cellulose nanofibril (CNF) hydrogels from recycled cellulose pulps (boxboard, milk containerboard, and fluting) and virgin birch cellulose pulp using a mechanical Masuko grinder. The mechanical disintegration of DES pretreated cellulose fibers resulted in highly viscous, gel-like cellulose nanofibril hydrogels with shear thinning behavior. According to transmission electron microscope (TEM) imaging, the nanofibrils had widths from $2 \mathrm{~nm}$ to $80 \mathrm{~nm}$, possessed the initial cellulose I crystalline structure, and had a crystallinity index of 53-56\%. The nanofibril hydrogels obtained were further used to produce low-cost, ultralight, highly porous, hydrophobic, and reusable superabsorbing aerogels that were used as efficient sponges to absorb oil and chemicals. The nanofibril sponges prepared by the consequent hydrophobic modification (silylation) of CNF hydrogels and freeze-drying had ultralow density $\left(0.003 \mathrm{~g} / \mathrm{cm}^{3}\right.$ ) and high porosity (up to $99.8 \%$ ). The sponges exhibited excellent oil/water absorption selectivity and ultra-high oil (marine diesel oil, kerosene, gasoline, motor
\end{abstract}


oil, castor oil, or linseed oil) and organic solvent (dimethyl sulfoxide, chloroform, n-hexane, toluene, acetone, or ethanol) absorption capacity. The nanofibril aerogels showed particular selectivity for marine diesel oil absorption from an oil-water mixture and possessed ultra-high absorption capacities of up to $143 \mathrm{~g} / \mathrm{g}$, which were much higher than the commercial absorbent materials (i.e., polypropylenes) (9-27 g/g) used as references. Additionally, the absorbed oil could be recovered by means of simple mechanical squeezing, and the superabsorbent could be reused for at least 30 cycles.

Keywords: aerogel, cellulose nanofiber, deep eutectic solvent, nanocellulose hydrogel, oil removal, silylation, sponge.

\section{Contents}

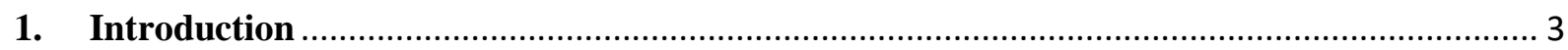

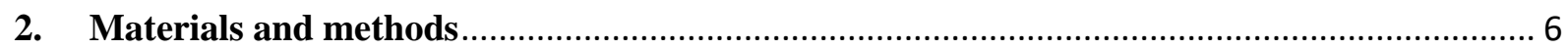

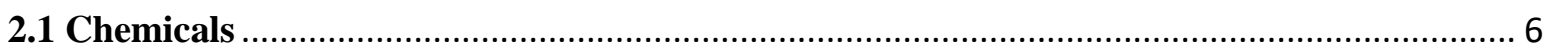

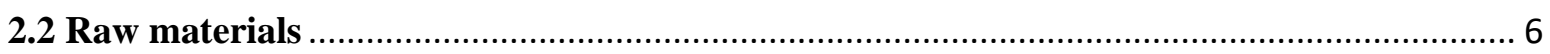

2.2.1 DES pre-treatment and preparation of CNF hydrogels ................................................ 7

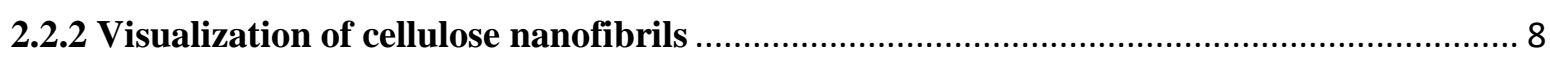

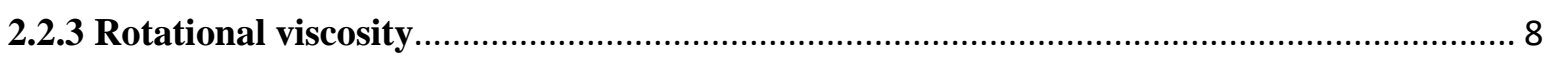

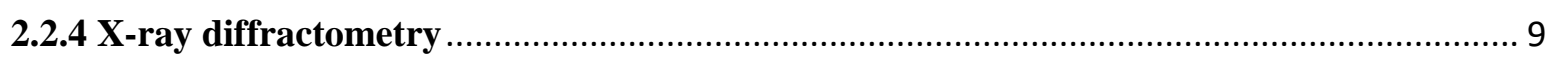

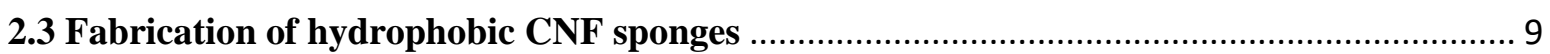

2.3.1 Density and porosity of CNF sponges and reference polypropylene absorbents.............. 10

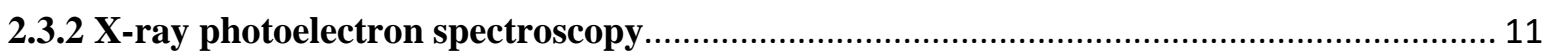

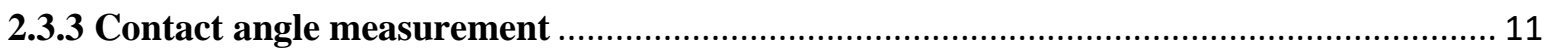

2.3.4 Field emissions electron microscopy (FESEM) characterization.................................... 11

2.4 CNF sponges' diesel oil sorption selectivity from oil-water mixtures ................................. 12

2.5 Absorption capacities for various oils and organic solvents............................................. 12

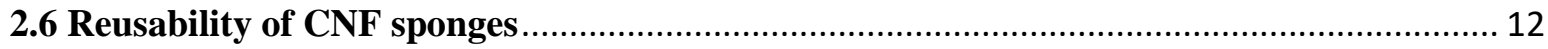

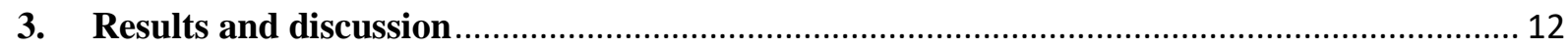

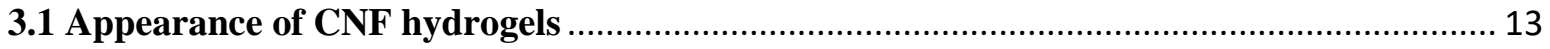

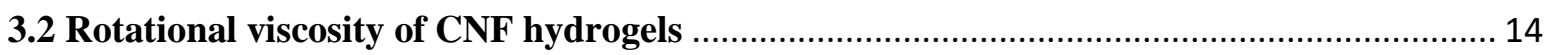

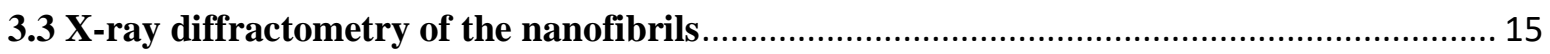

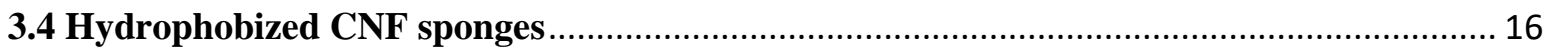

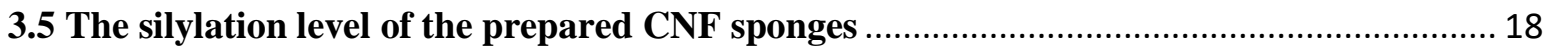

3.6 Diesel oil sorption selectivity of CNF sponges in oil-water mixtures ................................. 19

3.7 CNF sponges' absorption capacities for various oils and solvents.................................... 21 


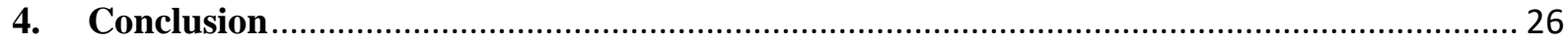

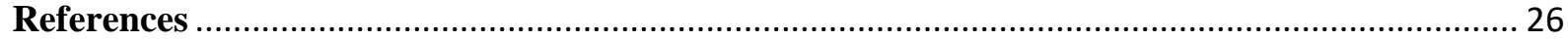

\section{Introduction}

Cellulose nanofibrils (CNFs) are elemental constituents of plant fibers and possess unique mechanical and chemical properties, including superior strength and low density $[1,2]$. Due to their very high water retention capacity [3] which is attributed to their hydrophilic surface hydroxyl groups, CNFs form highly viscous, shear thinning hydrogels with low solids contents. These hydrogels are attractive green alternatives to allow for the development of novel highend applications. However, the individualization of intact nanofibrils and the production of their hydrogels are complicated and require intensive mechanical treatments because of the strong hydrogen-bonded structures of cellulose materials. Therefore, several different chemical and enzymatic pretreatments have been proposed to loosen the rigid structure of cellulose. Among the most promising new green chemicals to facilitate the production of CNFs and their hydrogels are deep eutectic solvents (DESs), which are readily available green compounds that have low toxicity and, in many cases, are biodegradable [4]. DESs are typically synthesized by complexation of a halide salt of quaternary ammonium or phosphonium cation as the hydrogen bond acceptor (HBA), along with a hydrogen bond donor (HBD) (e.g., urea, glycerol, or ethylene glycol), to form a mixture that exhibits a notable lower melting point when compared to either HBA or HBD alone. The deep eutectic solvent system used in this research is based on choline chloride-urea as a pretreatment for the nanofibrillation of wood cellulose [5].

The CNF hydrogels can further be processed into various materials. Recently, the novel cellulose aerogels (also designated as cellulosic sponges or foam in the literature) based on CNF hydrogels have attracted considerable research interest due to their renewability, good mechanical properties, low density, high porosity, natural biodegradability, and environmental friendliness. These fascinating properties make it possible to use them as absorbents for oils and chemicals [6-12], for example. The aerogels can be prepared by freeze-drying the CNF hydrogel and removing all moisture while maintaining the porous, entangled 3D network structure of the CNFs. However, due to the presence of abundant hydroxyl groups, native cellulose aerogels display amphiphilicity (i.e., poor selectivity in absorbing hydrophobic compounds, such as oil, and high moisture absorption capacity) [13-15] The hydrophobicity of 
the surfaces can be encouraged or created by introducing roughness (i.e., micro- or nanoscale asperities) and low surface energy substances. Typically, hydrophobicity is evaluated in terms of wettability by measuring the water contact angle (WCA) on material surfaces. Depending on their WCA value, materials are classified as hydrophilic, hydrophobic, or superhydrophobic. Materials with a WCA of less than $90^{\circ}$ are described as hydrophilic; materials with WCAs of between $90^{\circ}$ and $150^{\circ}$ are hydrophobic; and those with WCAs of more than $150^{\circ}$ are superhydrophobic [16].

High-capacity hydrophobic absorbents based on green materials are strongly desired for removing environmental pollutants, such as oil and chemicals spilled in the aqueous environment. For example, it has been estimated that 224000 tons of oil from oil tanker spills was released into the global marine environment between 2000 and 2011 [17]. In the explosion and sinking of the Deepwater Horizon oil rig in the Gulf of Mexico in 2010, the British Petroleum pipe had been leaking oil and gas on the ocean floor about 42 miles off the coast of Louisiana. By the time the well was capped 87 days later, an estimated 3.19 million barrels of oil had leaked into the Gulf, making the oil spill the largest accidental ocean spill in history. The potential magnitude of the environmental threat of oil pollutants can be gauged by the fact that $1 \mathrm{~L}$ of benzene can effectively render several million gallons of water unfit for human consumption [18]. Moreover, oil-contaminated water has a disastrous effect on aquatic and terrestrial life forms, and also threatens human health and the economy — particularly tourismdue to its coating properties, unsightliness, and offensive odor [19]. Thus, there is an urgent demand across the world to develop a variety of technologies for the removal of oil and chemical pollutants from contaminated water sources.

Among the different clean-up methods available, such as in situ burning, mechanical methods, chemical treatments, and bioremediation alternatives, absorption through the use of oil and chemical sorbents is generally considered to be the optimal technological approach because of its relatively low cost, high efficiency, and production of less secondary pollution [17]. However, the feasibility of absorbents depends on their characteristics and performance. Hydrophobicity is one of their most important properties as highly hydrophobic absorbents [20, 21] exhibit more efficient absorption of oil and many chemicals than low-hydrophobic absorbents. The cost of the absorbents must remain low due to the large volumes required for cleaning up such spills. Their environmental impact and costs are also affected by their ability to be reused and recycled. Overall, the capacity of absorbents is associated with their porosity and interaction with the contaminant (e.g., superhydrophobicity). Therefore, sustainable 
materials with superhydrophobic properties, good absorption selectivity, ability to float (buoyancy), recyclability, and cost efficiency are especially needed [22].

Conventional oil and chemical sorbent materials can be grouped into three major classes: inorganic mineral sorbents, synthetic polymer sorbents, and natural organic sorbents [23]. Inorganic mineral sorbents, also known as sinking sorbents, are highly dense, fine-grained mineral or inorganic materials (natural or processed) used to sink floating oil. Examples include fly ash [24], zeolites [25], exfoliated graphite [26], activated carbon [27], organoclay [28], silica nanoparticles [29], and silica aerogels [30]. Currently, these mineral sorbents are not widely used because of their low oil-sorption capacities (typically less than 20 times by weight), poor oil/water selectivity, and low buoyancy, which makes them difficult to recycle. Due to their inherent oleophilicity and hydrophobicity, synthetic polymer oil and chemical sorbents, including polypropylene fibers [31], polyurethane foams [32], and polypropylene nonwoven webs [33], are the commercial sorbents most commonly used to clean up spills. Despite their moderate oil-sorption capacities, one major drawback of these sorbents is that they degrade or disintegrate very slowly, so their environmental and ecological effects are greater than those of mineral or natural products $[34,35]$. In contrast, natural organic sorbents, including kapok [36], sugarcane bagasse [37], cotton [38], rice straw [39], and wood chips [40], are eco-friendly alternatives for removing oil and chemicals from wastewater. They have moderate oil-sorption capacities (i.e., 3-50 times their own weight), which is comparable or sometimes lower density than inorganic and synthetic sorbents, and excellent biodegradability [41, 42]. Other advantages include their recyclability, their ability to recover oil and chemicals relatively easily, and the simplicity of their disposal when compared to other types of conventional sorbents. Despite these advantages, the majority of traditional natural sorbents also have many drawbacks, including poor buoyancy/floatability and poor selectivity of oil or chemical sorption, which is due to the relatively high water uptake of these inherently hydrophilic materials.

Here, the fabrication of CNF hydrogels based on a DES pretreatment and the use of hydrogels for the preparation of superabsorbent aerogels for the cleaning of oil and chemical spills is introduced. The CNF hydrogels were obtained from cost-effective recycled cellulose fibers (boxboard, milk containerboard, and fluting) using a simple, environmentally friendly nanofibrillation treatment involving a DES of choline chloride-urea. The CNF sponges were further synthesized from the hydrogels using a straightforward approach based on a reaction caused by a combination of two silylation agents followed by freeze-drying. The CNF aerogels had an ultra-low density $\left(0.0029 \mathrm{~g} / \mathrm{cm}^{3}\right)$, high porosity (up to $99.81 \%$ ), and were cost-effective, 
reusable, and hydrophobic. The increase in paper consumption has yielded a huge amount of paper waste which contributes to $25-40 \%$ of global municipal solid waste [43]. Recycling paper waste will help to preserve forests as well as solve an environmental problem. Recycled cellulose fibers from paper waste are a cheap and abundant resource. Combining an aerogel structure with recycled cellulose fiber will form a new material that is cost-effective and promising in terms of its oil absorption. Prepared CNF sponges exhibited excellent oil/water selectivity and an ultra-high capacity to absorb oil (marine diesel oil, kerosene, gasoline, motor oil, castor oil, and linseed oil) and organic solvents (dimethyl sulfoxide, chloroform, n-hexane, toluene, acetone, and ethanol). In addition, the absorbed oil was readily recovered by means of simple mechanical squeezing, and the superabsorbent aerogel could be reused for at least 30 cycles.

The chapter describes basic principle of the manufacturing CNF hydrogels, which can be further processed into superabsorbent aerogels and how they can be utilized for the cleaning of oil and chemical spills. Utilization of renewable resources, low cost raw materials and simple and environmentally friendly manufacturing process make these superabsorbents possible alternative for cleaning of chemical spills in the near future.

\section{Materials and methods}

\subsection{Chemicals}

Urea (97\%) and choline chloride (> 98\%) for DES were purchased from Borealis (Austria) and Algry Qu Mica (Spain), respectively. Methyltrimethoxysilane (98\%, MTMS) was obtained from Evonik Industries (Germany), and Hexadecyltrimethoxysilane (> 85\%, HDTMS) was purchased from Sigma-Aldrich (Germany). Lightweight marine diesel oil and kerosene were obtained from Neste (Finland), and gasoline (E95) and motor oil (5w40) were purchased from a local gas station. Dimethyl sulfoxide (> 99\%, DMSO) was obtained from TCI (Germany). Castor oil, linseed oil, chloroform (> 99\%), n-hexane (> 98\%), toluene (> 99.9\%), acetone (> 99.8\%), and ethanol (> 99.9\%) were obtained from VWR (Finland). All chemicals were used as received, without further purification. Two different types of commercial oil absorbent booms obtained from local rescue services were used as reference absorbents.

\subsection{Raw materials}

Recycled boxboard and milk containerboard were collected directly from board-container collections, and fluting board was supplied by Heinola Fluting (Finland). A dry sheet of industrially bleached birch kraft pulp (Betula verrucosa) was used as a reference cellulose raw 
material. All pulps were first pulped without chemicals using a Kenwood KM020 pulper (UK), which has an operating principle similar to that of the Hobart pulper, at a consistency of $1.5 \%$ at approximately $45^{\circ} \mathrm{C}$ using a rotor speed of 2 for $10 \mathrm{~min}$, and then washed and screened using a Somerville screen (Lorentzen \& Wettre, Sweden).

\subsubsection{DES pre-treatment and preparation of CNF hydrogels}

To pretreat the cellulose pulps (boxboard, milk containerboard, fluting, and birch kraft), a DES solution was produced by heating $1620 \mathrm{~g}$ of choline chloride and $1223 \mathrm{~g}$ of urea in a large beaker $\left(5 \mathrm{dm}^{3}\right)$ at $100{ }^{\circ} \mathrm{C}$ until the mixture melted, after which it was placed into a water bath at $100{ }^{\circ} \mathrm{C}$ under constant stirring for approximately $5 \mathrm{~min}$ to obtain a clear, colorless liquid. Then, $25 \mathrm{~g}$ (abs) of cellulose material (moisture content of $\sim 30 \%$ ) was added to the suspension and mixed for $2 \mathrm{~h}$, after which the beaker was removed from the water bath and $1000 \mathrm{~cm}^{3}$ of deionized water was added while mixing [4]. Then, the treated cellulose was washed with water using a Somerville screen (Lorentzen \& Wettre, Sweden) until clear rinse water was obtained. Next, four batches of each pulp were treated with DES prior to nanofibrillation with a Masuko supermasscolloider grinder MKCA6-2J (Japan) (Fig. 1) to obtain cellulose nanofibril hydrogels. The stones of the grinder were first carefully brought into close contact, as observed by the low friction sound, and then the pretreated pulp slurry was poured into the grinder at a consistency of $1.5 \%$. The pulp was passed through the grinder twice using a zero-grinding stone gap; then, the stones were adjusted to negative gap values to begin the actual nanofibrillation. The pulps were passed through the grinder a total of 10 times, using negative gap values of -20 $\mu \mathrm{m},-40 \mu \mathrm{m},-50 \mu \mathrm{m},-70 \mu \mathrm{m}$, and $-80 \mu \mathrm{m}$ to obtain viscous CNF hydrogels. 


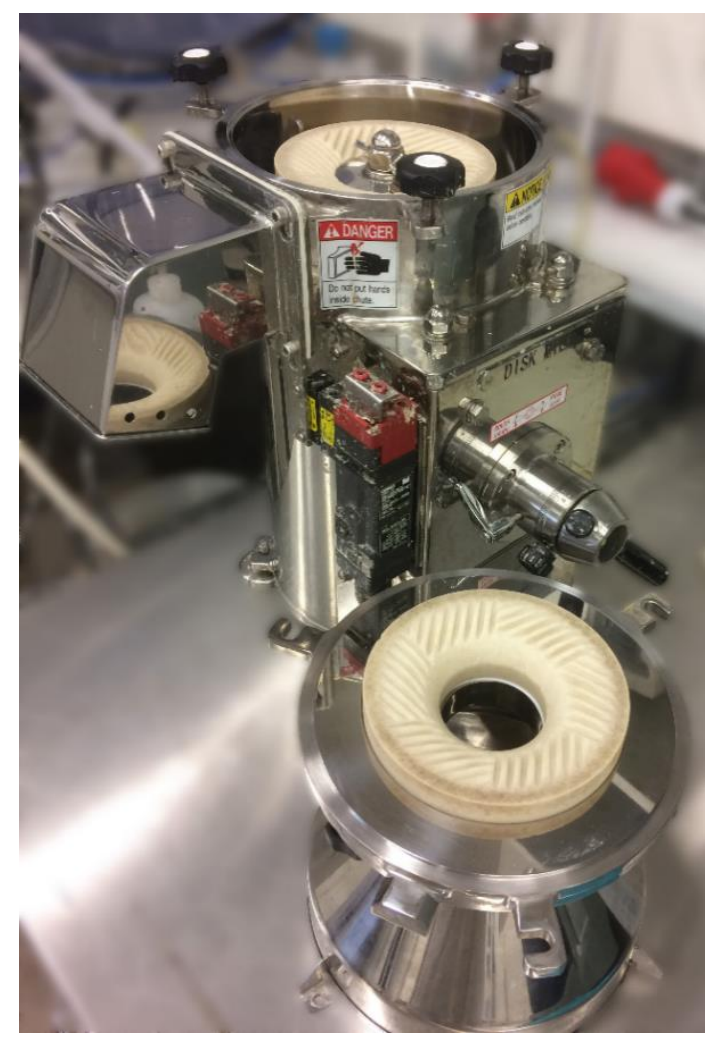

Fig 1. Masuko supermasscolloider grinder MKCA6-2J and grinding stones.

\subsubsection{Visualization of cellulose nanofibrils}

A Tecnai G2 Spirit transmission electron microscope (TEM) (the Netherlands) was used to observe the morphology of the CNFs. Samples were diluted with ultrapure water and a small drop of the diluted nanofibril suspension was placed on a carbon-coated and polylysine-treated copper grid, and any excess sample was removed from the edge of the grid with filter paper. Negative staining of the samples was performed by placing a droplet of uranyl acetate $(2 \% \mathrm{w} / \mathrm{v})$ on top of each specimen. The excess uranyl acetate was removed with filter paper as described above. The grids were dried at room temperature and analyzed at $100 \mathrm{kV}$ under standard conditions. Images were captured using a Quemesa CCD camera and ITEM image analysis software (Olympus Soft Imaging Solutions GMBH, Germany) was used to measure the width of the individual cellulose nanofibrils.

\subsubsection{Rotational viscosity}

Viscosity measurements of the CNF hydrogels were performed with the Brookfield DV-II+ Pro EXTRA (USA) rotational viscometer. For these measurements, vane-shaped spindles (V-71, $\mathrm{V}-72$, and V-73) were used at rotational speeds of 10, 20, 50, and $100 \mathrm{rpm}$. The measurements 
were conducted at a sample consistency of $0.5 \%$ and at a constant temperature of $20{ }^{\circ} \mathrm{C}$, using a measurement time of 2-5 min for each rotational speed.

\subsubsection{X-ray diffractometry}

The crystallinity of the cellulose nanofibril was analyzed through wide-angle X-ray diffractometry (WAXD) using a Siemens D5000 diffractometer (USA); Cu Ka radiation ( $\lambda=$ $0.1542 \mathrm{~nm}$ ) was used for the measurements. As a pretreatment, the freeze-dried samples were pressed into tablets at a thickness of $1 \mathrm{~mm}$, and the scans were taken over a $2 \theta$ (Bragg angle) range from $5^{\circ}$ to $50^{\circ}$ at a scanning speed of $0.02^{\circ} / \mathrm{s}$, using a step time of $1 \mathrm{~s}$. The degree of crystallinity, or the crystallinity index (CrI), was calculated using the peak intensity of the main crystalline plane (200) diffraction $\left(\mathrm{I}_{200}\right)$ of $2 \theta$ at $22.8^{\circ}$ and a peak intensity of $2 \theta$ at $18.0^{\circ}$, which is associated with the amorphous fraction of cellulose $\left(\mathrm{I}_{\mathrm{am}}\right)$, according to Eq. (1) [44].

$$
\operatorname{CrI}=\left(\frac{I_{200}-I_{a m}}{I_{200}}\right) \times 100 \%
$$

\subsection{Fabrication of hydrophobic CNF sponges}

The CNF hydrogels were diluted with deionized water, homogenized using an Ultra-Turrax system set to $8000 \mathrm{rpm}$ for $30 \mathrm{~s}$, and their $\mathrm{pH}$ adjusted to 4 using $\mathrm{HCl}$. Various dilutions were used, depending on the sample (Table 1).

Table 1. Summary of CNF aerogel samples and references, and solids content of CNF hydrogels used for aerogels preparation.

\begin{tabular}{|l|c|c|}
\hline \multicolumn{1}{|c|}{ Material } & Abbreviation & Solids content of hydrogel [\%] \\
\hline DES Birch Cellulose & DES_Cel(1.0) & 1.0 \\
\hline DES Birch Cellulose & DES_Cel(0.5) & 0.5 \\
\hline DES Birch Cellulose & DES_Cel(0.3) & 0.3 \\
\hline DES Birch Cellulose & DES_Cel(0.2) & 0.2 \\
\hline DES Fluting Board & DES_Flu(0.5) & 0.5 \\
\hline DES Fluting Board & DES_Flu(0.3) & 0.3 \\
\hline DES Fluting Board & DES_Flu(0.2) & 0.2 \\
\hline DES Boxboard & DES_Boa(0.5) & 0.5 \\
\hline DES Boxboard & DES_Boa(0.3) & 0.3 \\
\hline DES Boxboard & DES_Boa(0.2) & 0.2 \\
\hline DES Milk Containerboard & DES_MCB(0.5) & 0.5 \\
\hline DES Milk Containerboard & DES_MCB(0.3) & 0.3 \\
\hline DES Milk Containerboard & DES_MCB(0.2) & 0.2 \\
\hline $\begin{array}{l}\text { Ref Boom Polypropylene Material } \\
\text { (strip) }\end{array}$ & Ref (strip) & - \\
\hline $\begin{array}{l}\text { Ref Boom Polypropylene Material } \\
\text { (plug) }\end{array}$ & Ref (plug) & - \\
\hline
\end{tabular}


The silane solutions (20 wt-\%) for the hydrophobization of CNFs were prepared by diluting MTMS and HDTMS in ethanol. After dilution, hydrolyzed silane solutions were mixed using a magnetic stirrer for $10 \mathrm{~min}$. Then, $25 \mathrm{wt}-\%$ of freshly prepared silane solutions (MTMS and HDTMS, ratio of 50:50) against $\mathrm{CNF}$ amounts were added by micropipette to the $\mathrm{CNF}$ suspensions and stirred with a magnetic stirrer at room temperature for $2 \mathrm{~h}$.

Silylated CNF hydrogels $\left(75 \mathrm{~cm}^{3}\right)$ were introduced into metallic, round molds $(77 \mathrm{~mm}$ in diameter and $20 \mathrm{~mm}$ in height), frozen in liquid nitrogen, and transferred to the vacuum chamber of the freeze-drying device (Scanvac Coolsafe 55-15 Pro, Denmark) for $72 \mathrm{~h}$ to obtain hydrophobized CNF sponges. The silylation levels of the prepared sponges were determined by X-ray photoelectron spectroscopy (XPS).

The $\mathrm{pH}$ adjusting process is essential to promote the hydrolyzation of the silanes and to form the silanol groups that will later react with the cellulose nanofibers. Xie et al. [45] reported that cellulose is not reactive to many chemicals, and often the OH-groups are not accessible. Generally, the hydrolysis of organosilanes under acidic $\mathrm{pH}$ conditions favors the formation of more reactive silanol groups as well as the retardation of their condensation rate, which makes them available to react with the $\mathrm{OH}$-groups of the fibers, or to condensate over the fiber surface.

\subsubsection{Density and porosity of CNF sponges and reference polypropylene absorbents}

The apparent volumetric mass density of CNF sponges and reference polypropylene materials was calculated using the following formula (Eq. 2):

$\rho=\frac{m}{V}$

where $m$ and $V$ are the mass $(\mathrm{g})$ and volume $\left(\mathrm{cm}^{3}\right)$ of the materials, respectively.

The porosity $(P, \%)$ of the CNF sponges and polypropylene materials was calculated according to Eq. (3):

$P=\frac{V-m / \rho_{c}}{V} \times 100 \%$

where $V\left(\mathrm{~cm}^{3}\right)$ is the volume of the materials, $m(\mathrm{~g})$ is the mass, and $\rho_{c}$ is the density of bulk cellulose $\left(1.528 \mathrm{~g} / \mathrm{cm}^{3}\right)$ or polypropylene $\left(0.9075 \mathrm{~g} / \mathrm{cm}^{3}\right)$. Density and porosity of CNF sponges and commercial reference materials is presented in Table 2. 


\subsubsection{X-ray photoelectron spectroscopy}

The silylation levels of the prepared sponges were determined by XPS using a Thermo Fisher Scientific ESCALAB 250Xi (UK). A monochromatic AlKo X-ray source operated at $300 \mathrm{~W}$ was used with a combination of an electron flood gun and ion bombardment for charge compensation. The take-off angle was $45^{\circ}$ in relation to the sample surface. Low-resolution survey scans were taken using a 1-eV step and a 150-eV analyzer pass energy, and the highresolution spectra were taken with a $0.1-\mathrm{eV}$ step and a $20-\mathrm{eV}$ analyzer pass energy. The binding energy (BE) scale was referenced to the $\mathrm{C} 1 \mathrm{~s}$ line of aliphatic carbon, set at $284.6 \mathrm{eV}$. All measurements were taken in an ultra-high vacuum pressure chamber $\left(5 \times 10^{-9} \mathrm{mbar}\right)$.

Prior to measurement, a dry sample was pressed on the indium film. Three measurements were taken from each of the silane-treated CNF sponges. The first measurement was on top of the aerogel, the second at the bottom, and the third in the center of the aerogel after it had been sliced into two halves. The untreated reference aerogel was measured only once, the center.

\subsubsection{Contact angle measurement}

The surface wettability of the CNF sponges was evaluated using contact angle measurement. The static contact angles of Milli-Q water droplets on the aerogel surfaces were measured at 22 ${ }^{\circ} \mathrm{C}$ and 10\% RH using a CAM 2000 (KSV Instruments Ltd, Helsinki, Finland). Measurements were performed by placing a $6.5-\mu \mathrm{L}$ drop of Milli-Q water on the aerogel surface using a syringe and capturing images at a rate of 1 frame/sec to be sent directly from the CCD camera to the computer for analysis. Determination of the contact angle was based on an analysis of the drop's shape using the full Young-Laplace equation and assuming a spherical drop. The WCAs at $60 \mathrm{~s}$ are reported. Five parallel measurements were taken at various positions on each aerogel sample, and the average values and standard deviation were calculated. Typical uncertainties in the experiments were less than $5^{\circ}$.

\subsubsection{Field emissions electron microscopy (FESEM) characterization}

To visualize the structure of the various CNF sponges, FESEM analysis was performed using a Zeiss Ultra Plus instrument (Zeiss, Germany). The samples were imaged using a low voltage ( $5 \mathrm{kV}$ ) and a working distance of $\sim 5 \mathrm{~mm}$. The CNF sponges were analyzed by simply placing each sample on a sample holder using a carbon pad and coating it with a thin layer of platinum. 


\subsection{CNF sponges' diesel oil sorption selectivity from oil-water mixtures}

A fresh sorbent sample $(0.05-0.1 \mathrm{~g})$ was placed on the surface of a solution having a 5-mm layer (i.e., $13.00 \mathrm{~g}$ ) of marine diesel oil floating on an 80-mm layer of water. The sample was left for $15 \mathrm{~min}$, and then the sorbent was removed and left to drip for $30 \mathrm{~s}$ before being weighed. The amount of oil left in the oil-water mixture was determined using gravimetric analysis, as accepted by the United States Environmental Protection Agency (US EPA). In this case, diesel oil extracted using a solvent (i.e., n-hexane) from an oil-in-water sample is the EPA-accepted method (EPA 1664) for oil-in-water analysis. After sorption testing, the residual oil-water mixture was acidified to a $\mathrm{pH}$ of 2 , and the sample was extracted three times using n-hexane. The combined collected extracts were distilled at $85{ }^{\circ} \mathrm{C}$ and weighed to determine absorption selectivity in terms of oil absorption capacity $(\mathrm{g} / \mathrm{g})$ and water uptake $(\mathrm{g} / \mathrm{g})$. At least three measurements were conducted for each sample, and the average value is presented.

\subsection{Absorption capacities for various oils and organic solvents}

In the absorption test, pre-weighed hydrophobic CNF sponges were placed in various oils (marine diesel oil, kerosene, gasoline, motor oil, castor oil, and linseed oil) and organic solvents (dimethyl sulfoxide, chloroform, n-hexane, toluene, acetone, and ethanol) for 2 min to reach absorption equilibrium and then removed and weighed. The sorption capacity ( $\mathrm{g} / \mathrm{g}$ ), defined as the mass of absorbed oil or solvent (g) per unit mass of dry absorbent (g), was used to characterize oil-absorption capacity. At least 3 measurements were conducted for each sample, and the average value is presented as an absorption result.

\subsection{Reusability of CNF sponges}

Mechanical compression was used to extract the remaining liquid from the sorbent so that reusability could be tested. The absorbed marine diesel oil was recovered by simple mechanical squeezing. The squeezed CNF sponges absorbed oil again without any post-treatment, and the oil stored in the sponges was measured again. Oil storage capacity, defined as the mass of oil (g) per unit mass of the dry sponge ( $\mathrm{g}$ ), and values presented as capacity left compared to fresh absorbents were used to characterize the reusability of the CNF sponges.

\section{Results and discussion}

A deep eutectic solvent based on choline chloride-urea was used as a pretreatment method to nanofibrillate recycled cellulose materials. Mechanical nanofibrillation (with a Masuko grinder) of the pretreated cellulose resulted in individual nanofibrils and an opaque CNF 
hydrogel. The method uses green bulk chemicals and can be considered a sustainable approach to obtain CNF without the need for toxic or expensive chemicals or other intensive mechanical and/or chemical modifications of the cellulose [46].

A few DESs are reported to dissolve cellulose [47], including a mixture of choline chloride and zinc chloride [48], and choline acetate with quaternary ammonium cation [49], when lowmolecular mass microcrystalline cellulose is used. Here, subjecting oven-dried, high-molecular weight cellulosic pulp to a DES mixture of choline chloride-urea with a molar ratio of 1:2 resulted in the disintegration of the cellulose into a solution without visible solubilization at 100 ${ }^{\circ} \mathrm{C}[4]$.

\subsection{Appearance of CNF hydrogels}

During the DES treatment (before mechanical disintegration), the fibers rapidly formed a transparent, non-fibrous gel in the solvent, and after the addition of water, the fibers recovered their initial forms. Therefore, the DES-treated fibers did not show any clearly visible changes in their structures after being washed with water. When exposed to further mechanical disintegration, CNF hydrogels were obtained from the DES-treated fibers.

The visual appearances of these hydrogels after 10 passes through the Masuko grinder are shown in Fig. 2. All of the CNF samples had gel-like, highly viscous appearances which indicate that the strong shear forces in the Masuko grinder break the hydrogen bonds in the loosened cell walls of the DES-treated cellulose fibers [2]. The choline chloride-urea was observed to promote the nanofibrillation of recycled fibers despite the high moisture content of the original cellulose material (approx. 70\%). This result confirms the recent findings of Du et al. [50] who stated that a small amount of water absorbed into the choline chloride-urea solution can even improve the electrolyte system in the DES because water links to urea via strong hydrogen bonds, which in turn promotes ionic dissociation by the generation of more free cationic choline ions [50].

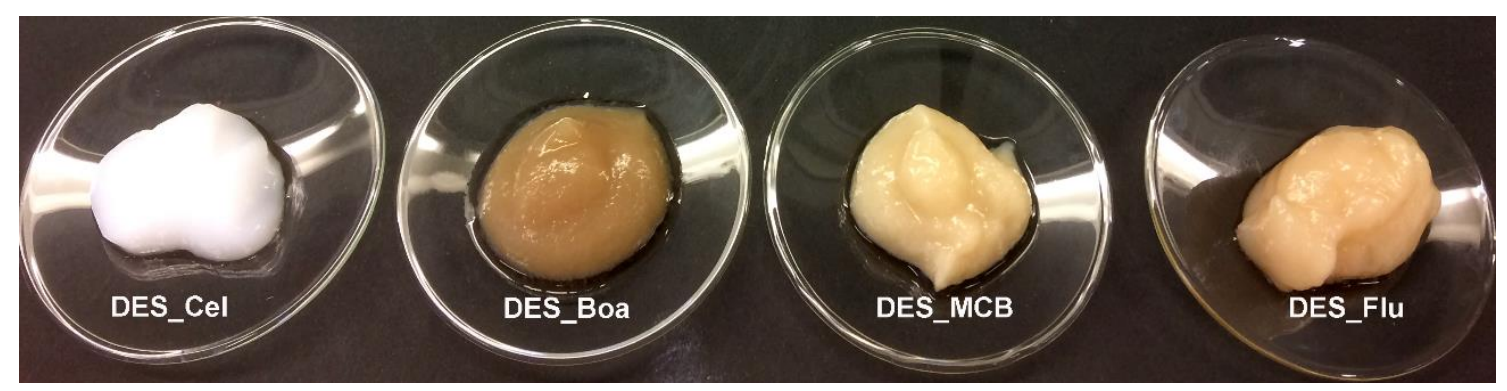


Fig. 2 Visual appearances of the CNF hydrogels (DES_Cel, DES_Boa, DES_MCB, and DES_Flu) after DES treatment and the $10^{\text {th }}$ pass through the Masuko grinder. Solids contents of the hydrogels were between 1.5 and $2.0 \%$.

Fig. 3 shows examples of TEM images of the CNFs after 10 passes through the Masuko grinder. The visual appearances of the CNFs from different cellulose sources differed only slightly, and they all possessed diameters of $2-80 \mathrm{~nm}$. Moreover, some larger aggregates were noted.
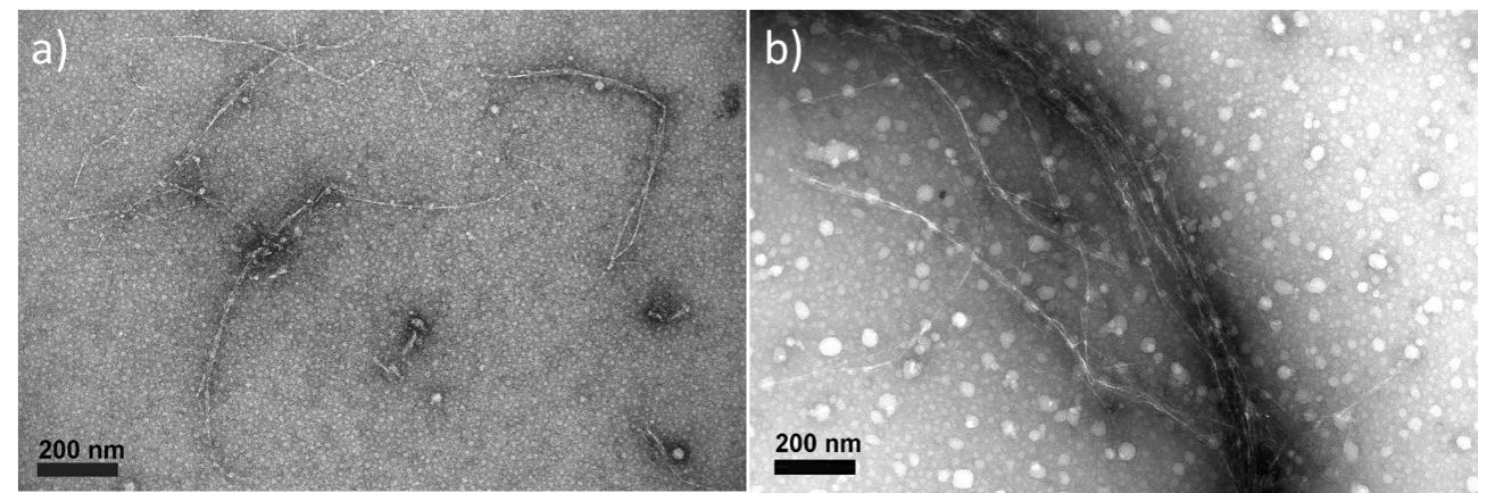

Fig. 3 TEM images of the DES_Flu (a) and DES_Boa (b). The white dots in the images are from the polylysine in the sample preparation.

\subsection{Rotational viscosity of CNF hydrogels}

Fig. 4 shows the rotational viscosities of the CNF hydrogels after their $10^{\text {th }}$ (Fig. $4 \mathrm{a}$ ) and the $8^{\text {th }}$ passes (Fig. 4b) through the Masuko grinder at a consistency of $0.5 \%$. The low shear rate viscosity of the hydrogel correlates with the morphology of cellulose nanoparticles [51], and the higher the viscosity, the thinner and longer the nanofibrils are for a given concentration [52]. Long and thin nanofibrils are able to form network structures in aqueous phases held together by numerous temporary hydrogen bonds and Van der Waals interactions [53]. This effect explains cellulose nanofibril hydrogels' thixotropic and shear thinning behavior that is related to the high aspect ratio of their particles [53, 54]. 


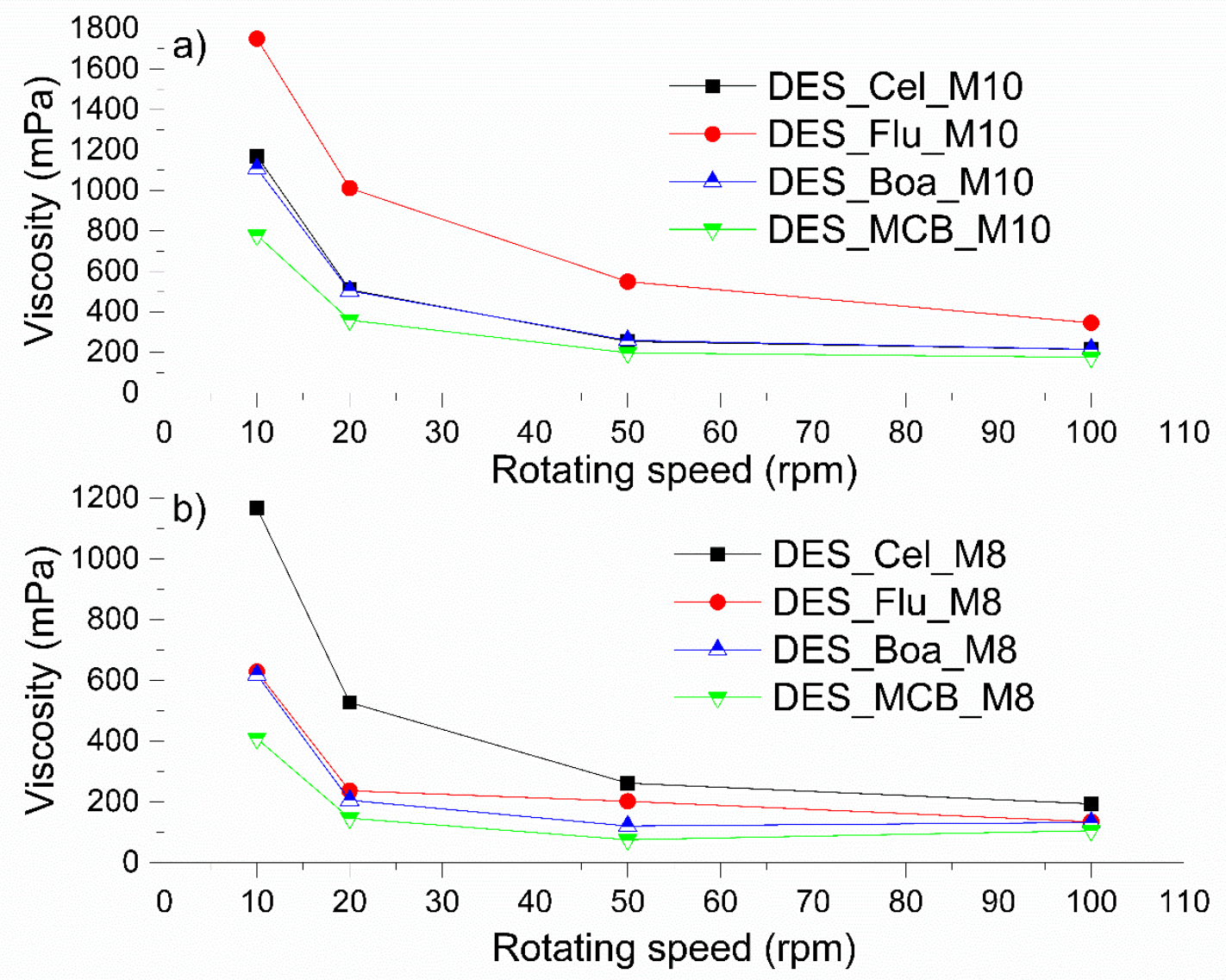

Fig. 4 Rotational viscosities of the CNF hydrogels (DES_Cel, DES_Flu, DES_Boa and DES_MCB) and Masuko-ground pulps a) after the $10^{\text {th }}$ pass, and b) after the $8^{\text {th }}$ pass of the Masuko grinder at a consistency of $0.5 \%$.

After eight passes through the Masuko grinder (Fig. 4b), the highest viscosity was observed for the CNF hydrogel obtained from virgin reference cellulose. However, all hydrogels showed high viscosity levels with shear thinning behavior after the $10^{\text {th }}$ pass, thereby indicating that high-performing CNF hydrogels could be obtained from recycled fiber material. The use of recycled cellulose materials has a notable cost benefit, since the price of recycled cellulose materials is only around $10 \%$ of the price of bleached birch cellulose. In practice, the cost of recycled cellulose materials is only around 80-100€/ton, whereas the cost of bleached birch cellulose is currently around $700-800 € /$ ton.

\subsection{X-ray diffractometry of the nanofibrils}

The X-ray diffractograms of the CNFs and the calculated crystallinity indexes are shown in Figs. 5a and 5b. The mechanical shearing caused a reduction in the crystallinity of the CNFs, and the largest reduction was noted after five Masuko grinder passes. The crystallinity index of 
the CNFs' tenth passes through the Masuko grinder varied from 56\% to 53\%, indicating that the CNFs still maintained their highly crystalline structure.

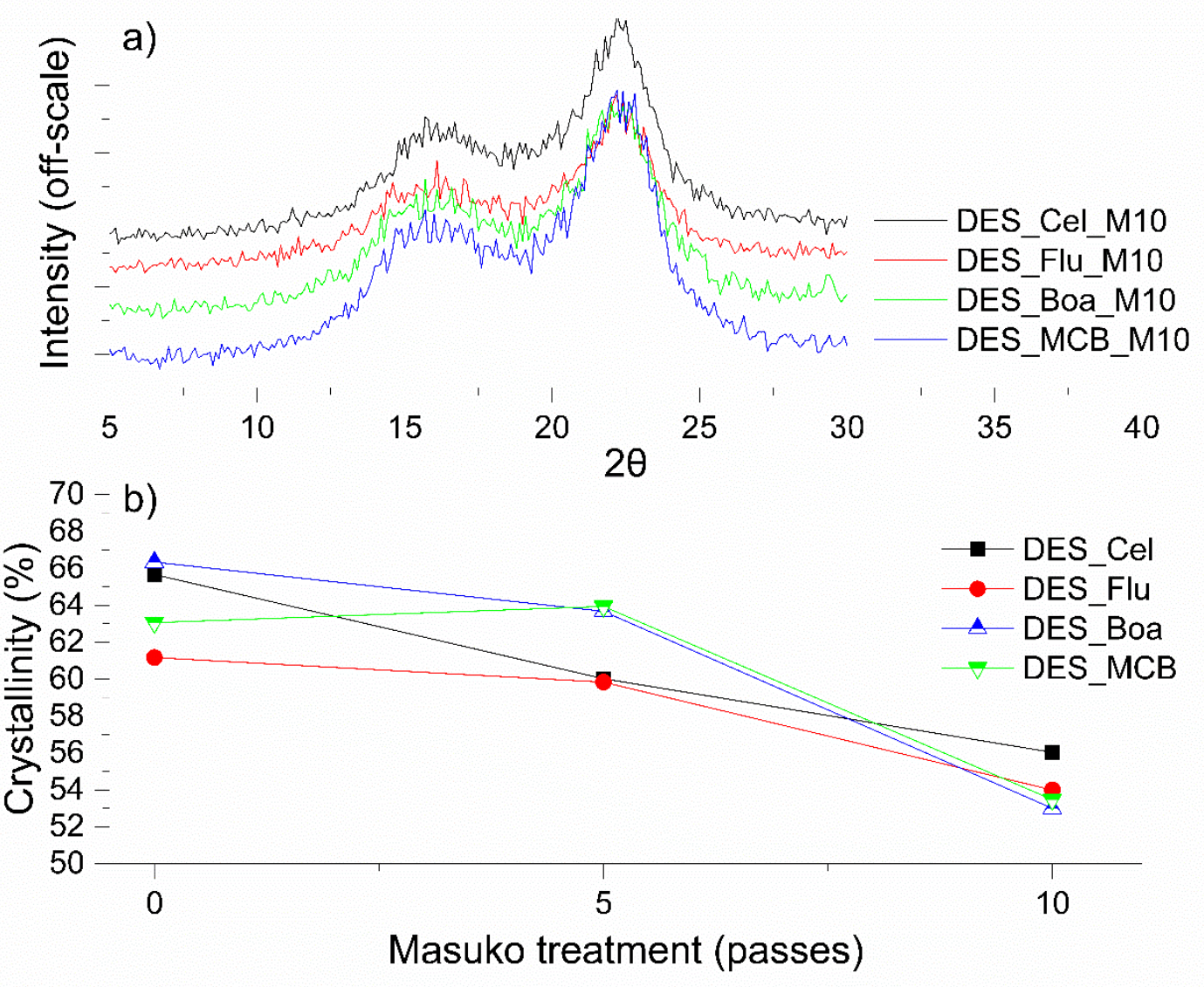

Fig. 5 a) The diffractograms of the CNFs and b) the calculated crystallinity indexes.

\subsection{Hydrophobized CNF sponges}

The hydrophobized aerogels were produced from CNF hydrogels using consequent silylation and freeze-drying treatments. The waste cellulose materials (boxboard, milk containerboard, and fluting) were compared to virgin, bleached birch cellulose and found to be of sufficient quality and to present no problems during either chemical modification or fibrillation.

To achieve the porous structure of the CNF sponges (Table 2) and to avoid the need for posttreatment, both silylation agents-MTMS and HDTMS - were mixed with hydrogels before the freeze-drying process to result in crosslinked CNF aerogels while simultaneously improving their hydrophobicity. MTMS is a crosslinking agent for cellulose $[8,55]$, while HDTMS is a silane containing a long carbon chain that can provide hydrophobicity in aerogels. The reaction medium was adjusted to an acidic $\mathrm{pH}$ of 4 to favor condensation of the hydrolyzed MTMS and HDTMS with the cellulose surface. At a $\mathrm{pH}$ of 4 , the hydrolysis of alkoxysilanes has been 
reported as rapid and the self-condensation limited, which maximizes the concentration of the silanol species available to interact with the cellulosic substrate [56].

Table 2. Density and porosity of CNF aerogels and commercial reference materials.

\begin{tabular}{|c|c|c|}
\hline Material & Density [g/cm ${ }^{\mathbf{3}}$ & Porosity [\%] \\
\hline DES_Cel(1.0) & 0.0166 & 98.91 \\
\hline DES_Cel(0.5) & 0.0070 & 99.54 \\
\hline DES_Cel(0.3) & 0.0042 & 99.72 \\
\hline DES_Cel(0.2) & 0.0029 & 99.81 \\
\hline DES_Flu(0.5) & 0.0079 & 99.48 \\
\hline DES_Flu(0.3) & 0.0049 & 99.68 \\
\hline DES_Flu(0.2) & 0.0032 & 99.79 \\
\hline DES_Boa(0.5) & 0.0075 & 99.51 \\
\hline DES_Boa(0.3) & 0.0045 & 99.71 \\
\hline DES_Boa(0.2) & 0.0031 & 99.79 \\
\hline DES_MCB(0.5) & 0.0079 & 99.48 \\
\hline DES_MCB(0.3) & 0.0048 & 99.69 \\
\hline DES_MCB(0.2) & 0.0033 & 99.78 \\
\hline Ref (strip) & 0.0807 & 91.11 \\
\hline Ref (plug) & 0.0521 & 94.26 \\
\hline
\end{tabular}

Table 2 shows the densities and porosities of the manufactured CNF sponges as a function of their CNF hydrogel solids content. Decreasing the solids content from $1.0 \%$ to $0.2 \%$ caused the density of the reference CNF sponge (DES_Cel) to decrease from $0.0166 \mathrm{~g} / \mathrm{cm}^{3}$ to $0.0029 \mathrm{~g} / \mathrm{cm}^{3}$ and the porosity to increase from $98.91 \%$ to $99.81 \%$. Compared to commercial oil absorption materials (i.e., polypropylene from commercial oil absorbent booms), the density of the CNF sponges was up to 28 times less and the porosity more than $8 \%$ more (Table 2).

Fig. 6 shows the morphologies of the sponges made from recycled board and reference cellulose CNFs (DES_Boa and DES_Cel) with and without hydrophobic modification. Without silylation, the DES_Boa sponge possessed a continuous three-dimensional (3D) porous structure (Fig. 6a) that was formed by randomly entangled nanofibrils. Hydrophobic modification with the aid of a crosslinking agent resulted in the formation of a continuous, sheet-like coating. As demonstrated, the porous structure was well maintained (Figs. 6b and 6d). In addition, the waste board celluloses formed a well-structured texture when compared to the virgin cellulose aerogel (Figs. 6a-6d). 

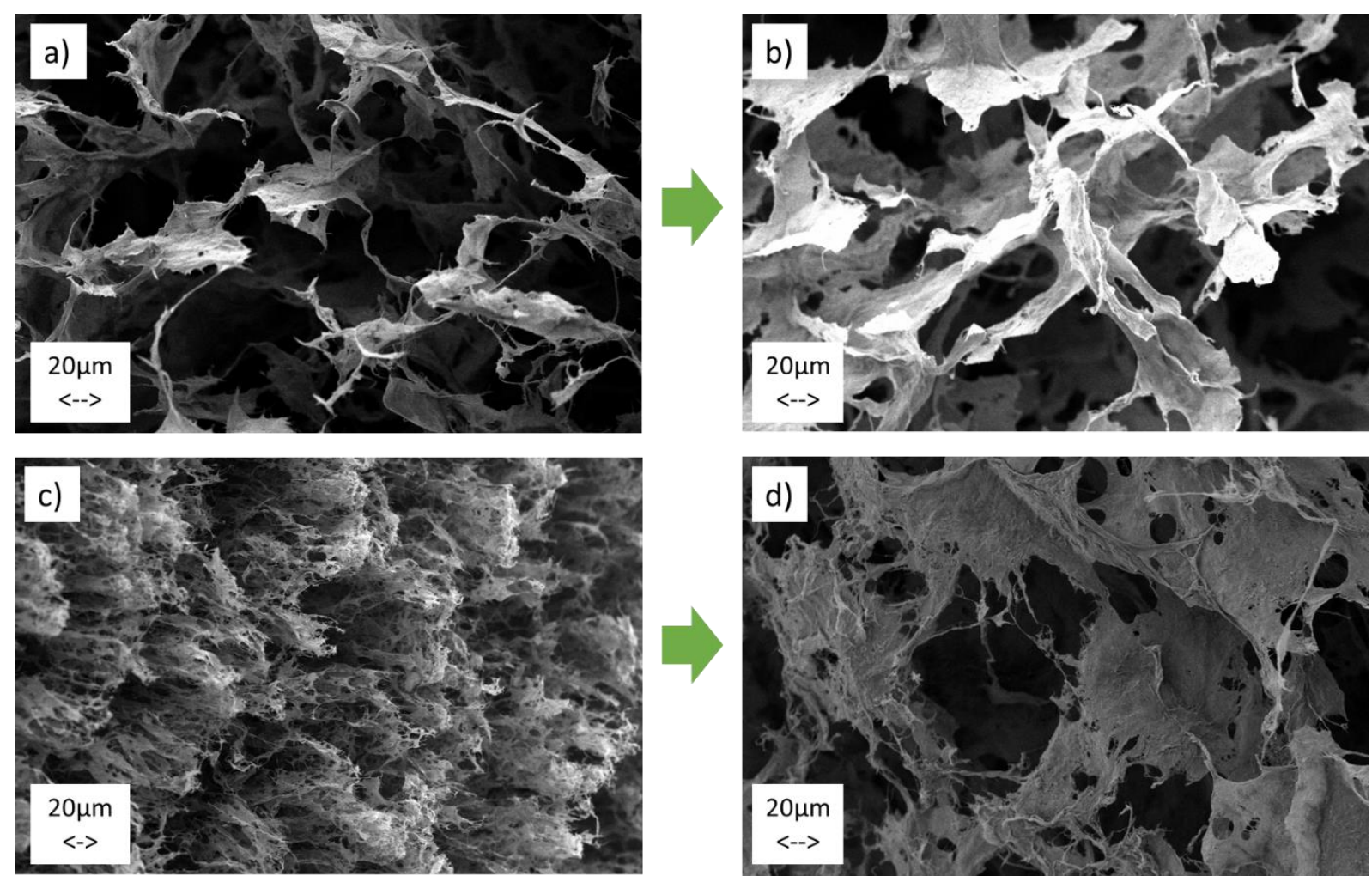

Fig. 6 FESEM images of CNF sponges: (a) unmodified DES_Boa (0.5), (b) modified DES_Boa (0.5), (c) unmodified DES_Cel (0.5), and (d) modified DES_Cel (0.5).

To indicate the hydrophobicity of silylated CNF sponges, their WCAs were determined (Table 3). All aerogels were evidently hydrophobic (i.e., WCA $>90^{\circ}$ ), and a sample of fluting celluloses (DES_Flu) could even be characterized as superhydrophobic (i.e., WCA > $150^{\circ}$ ). Based on visual observations, the water droplets easily rolled off the silylated CNF aerogels when the sliding angle was increased slightly, thereby confirming the hydrophobic nature of all silylated CNF sponges.

Table 3. Water contact angles (WCAs) of various CNF aerogels with $0.5 \%$ solids content.

\begin{tabular}{|c|c|c|}
\hline Aerogel & WCA [deg] & WCA [std] \\
\hline DES_Cel & 142.9 & 6.65 \\
\hline DES_Flu & 159.0 & 4.58 \\
\hline DES_Boa & 107.2 & 4.45 \\
\hline DES_MCB & 129.4 & 4.90 \\
\hline
\end{tabular}

\subsection{The silylation level of the prepared CNF sponges}

Effective oil/water selectivity is essential for oil absorbents [9]. It should be noted that freezedried CNF sponges cannot be directly used as oil absorption materials due to the large number of hydrophilic hydroxyl groups in unsilylated cellulose fibers. Hydrophilic aerogels disintegrate 
rapidly in water because water penetrates the aerogel, destroying the hydrogen bonds between the CNFs and causing the aerogel structure to collapse.

The silylation of sponges was confirmed and quantified using X-ray photoelectron spectroscopy (XPS). Without silylation, the surface concentration of silicon in various DES-treated CNF sponges varied from $0.46-0.76$ at- $\%$, whereas after silylation, a strong peak of silicon was noted, and the surface concentration of silicon in these samples varied from 4.47-6.27 at-\% (Table 4). In addition, the present study analyzed the spatial distribution of silicon on the top phase, the inner phase, and the bottom phase of the aerogel. The silicon contents were very similar (variation within $0.4 \%$ ), except for that of DES_MCB (variation of 0.76\%), which confirmed the successful, homogenous silane treatment of the aerogels (Table 4).

Table 4. Silicon content of various CNF aerogels with $0.5 \%$ solids content.

\begin{tabular}{|c|c|c|}
\hline Aerogel & $\begin{array}{l}\text { Surface concentration of Si on } \\
\text { unmodified samples [at-\%]* }\end{array}$ & $\begin{array}{c}\text { Surface concentration of } \mathrm{Si} \text { in } \\
\text { silylated samples [at-\%] }\end{array}$ \\
\hline DES_Cel & 0.47 & $4.47 \pm 0.27$ \\
\hline DES_Flu & 0.74 & $5.00 \pm 0.34$ \\
\hline DES_Boa & 0.74 & $6.27 \pm 0.36$ \\
\hline DES_MCB & 0.46 & $4.80 \pm 0.76$ \\
\hline
\end{tabular}

\subsection{Diesel oil sorption selectivity of CNF sponges in oil-water mixtures}

To investigate the selectivity of oil sorption of various CNF sponges, a mixture of marine diesel oil and water was prepared. Fig. 7 shows the oil absorption capacities of various DES-treated hydrophobic CNF sponges. All CNF sponges investigated demonstrated similar proclivities against porosity (i.e., solids content). With a solids content of $0.5 \%$, all materials had nearly the same oil absorption capacity (from $88-97 \mathrm{~g} / \mathrm{g}$ ), while at higher porosities (i.e., $<0.5 \%$ ), DES_Cel had the highest capacity. Evidently, with increased DES_Cel sponge porosity (i.e., solids content from 1.0 to $0.2 \%$ ), the absorption capacities for marine diesel oil increased significantly, from 52 to $143 \mathrm{~g} / \mathrm{g}$. Therefore, the CNF sponges with lower density and higher porosity possessed higher oil absorption capacities. 


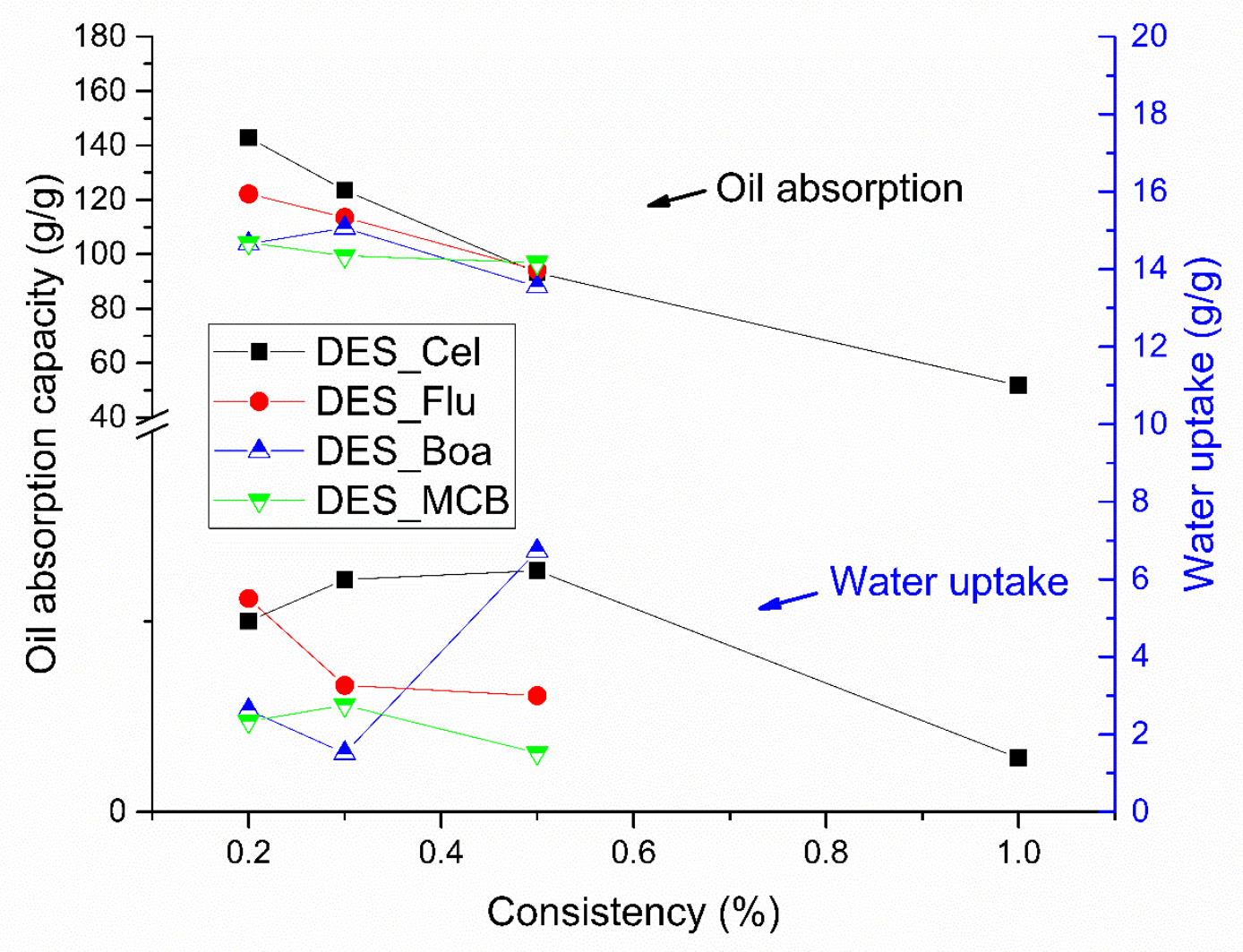

Fig. 7 Oil absorption capacities (left y-axis) and water uptake (right y-axis) of various CNF aerogels.

The water uptake, or water absorption, of various CNF aerogels was also determined, and the results are presented in Fig. 7 (right y-axis). In all cases, the water absorption of various CNF sponges was very low $(<7 \mathrm{~g} / \mathrm{g})$ when compared to their marine diesel oil absorption (left $\mathrm{y}$-axis of Fig. 7), suggesting that the various DES-treated hydrophobic CNF sponges had excellent selectivity toward diesel oil. Compared to the capacity of DES_Cel (0.3) to absorb water (6.0 g/g), DES_Cel capacity to absorb marine diesel oil could be as much as 21 times higher.

To achieve a very high absorption capacity (>100 g/g), CNF sponges should have the highest possible porosity and clear hydrophobicity. When porosity beyond $99.8 \%$ was achieved, problems were encountered because the strength of the CNF sponges was so diminished that handling them was a challenge. Another problem was that absorbed oil easily poured out from the aerogel structure after the oil sorption test, meaning that in practice the aerogel cannot retain all the oil that it absorbs. 


\subsection{CNF sponges' absorption capacities for various oils and solvents}

The present study also investigated the capacity of hydrophobic CNF sponges to absorb a wide range of other oils and organic solvents, as shown in Fig. 8. Overall, the CNF sponges exhibited excellent oil absorption capacities. For example, DES_Cel (0.3) had a capacity of $124 \mathrm{~g} / \mathrm{g}$ for marine diesel oil, $90 \mathrm{~g} / \mathrm{g}$ for kerosene, $92 \mathrm{~g} / \mathrm{g}$ for gasoline, $120 \mathrm{~g} / \mathrm{g}$ for motor oil, and $150 \mathrm{~g} / \mathrm{g}$ for linseed oil.

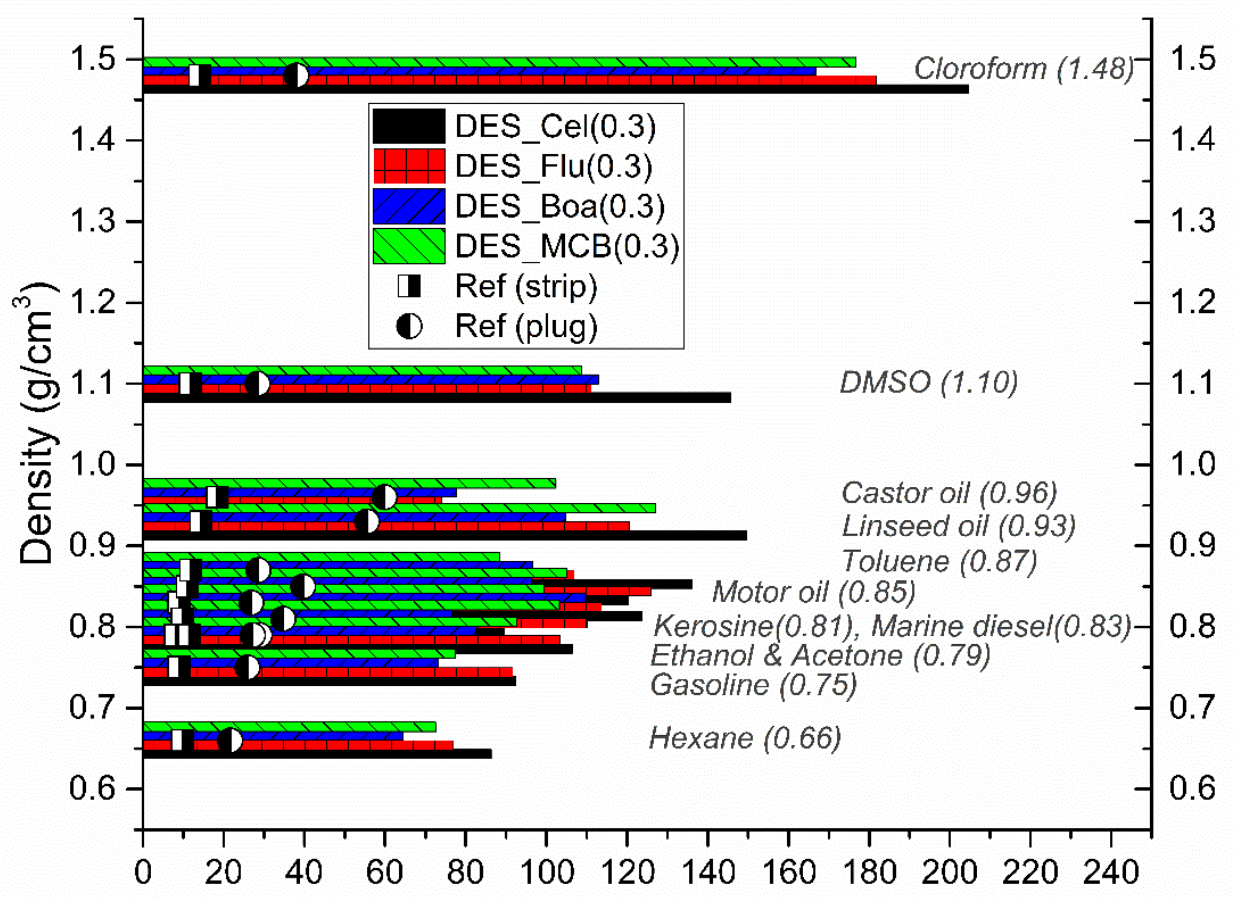

Absorption capacity $(\mathrm{g} / \mathrm{g})$

Fig. 8 Absorption capacities of various $\mathrm{CNF}$ aerogels and reference materials by the densities of oils and solvents.

All CNF sponges also showed ultra-high capacities to absorb a wide range of organic solvents, ranging from $65 \mathrm{~g} / \mathrm{g}$ for hexane to $205 \mathrm{~g} / \mathrm{g}$ for chloroform, depending on the density of the liquid (Fig. 8). These capacities could be attributed to the high porosity (99.72\%) and hydrophobicity of the material. Comparing the results obtained for CNF sponges to those for commercial reference absorption materials (Ref (strip) and Ref (plug)), all the CNF sponges created had notably higher capacities to absorb all oils and organic solvents investigated. For instance, the DES_Cel (0.3) sponge had an absorption capacity of $120 \mathrm{~g} / \mathrm{g}$ for motor oil and $136 \mathrm{~g} / \mathrm{g}$ for toluene, while the DES_Boa (0.3) sponge had an absorption capacity of $96 \mathrm{~g} / \mathrm{g}$ for motor oil 
and $97 \mathrm{~g} / \mathrm{g}$ for toluene. In contrast, the Ref (strip) had an absorption capacity of only $11 \mathrm{~g} / \mathrm{g}$ for motor oil and $12 \mathrm{~g} / \mathrm{g}$ for toluene, and the Ref (plug) had values of $40 \mathrm{~g} / \mathrm{g}$ and $29 \mathrm{~g} / \mathrm{g}$ for these two liquids, respectively.

\subsection{Reusability of CNF sponges to absorb marine diesel oil}

Fig. 9 shows the absorption and reusability performances of the hydrophobic DES_MCB (0.5) sponge in absorbing marine diesel oil. Fig. 9a shows how a water droplet stayed on the cleavage plane of the aerogel, thus indicating the CNF sponge's hydrophobicity. The sponge could be saturated with marine diesel oil in less than $30 \mathrm{~s}$ (Fig. 9b), thereby exhibiting its high absorption efficiency. In addition, the absorbed oil could easily be recovered by simple mechanical squeezing (Figs. 9c and d). Furthermore, the squeezed sponge could quickly reabsorb more oil over a period of about $30 \mathrm{~s}$ and recovered most of its volume without any post-treatment. Fig. 9e demonstrates the appearance of DES_MCB (0.5) after 30 cycles of mechanical squeezing and reabsorption of diesel oil, demonstrating the sponge's efficiency in recovering oil and its reusability. 


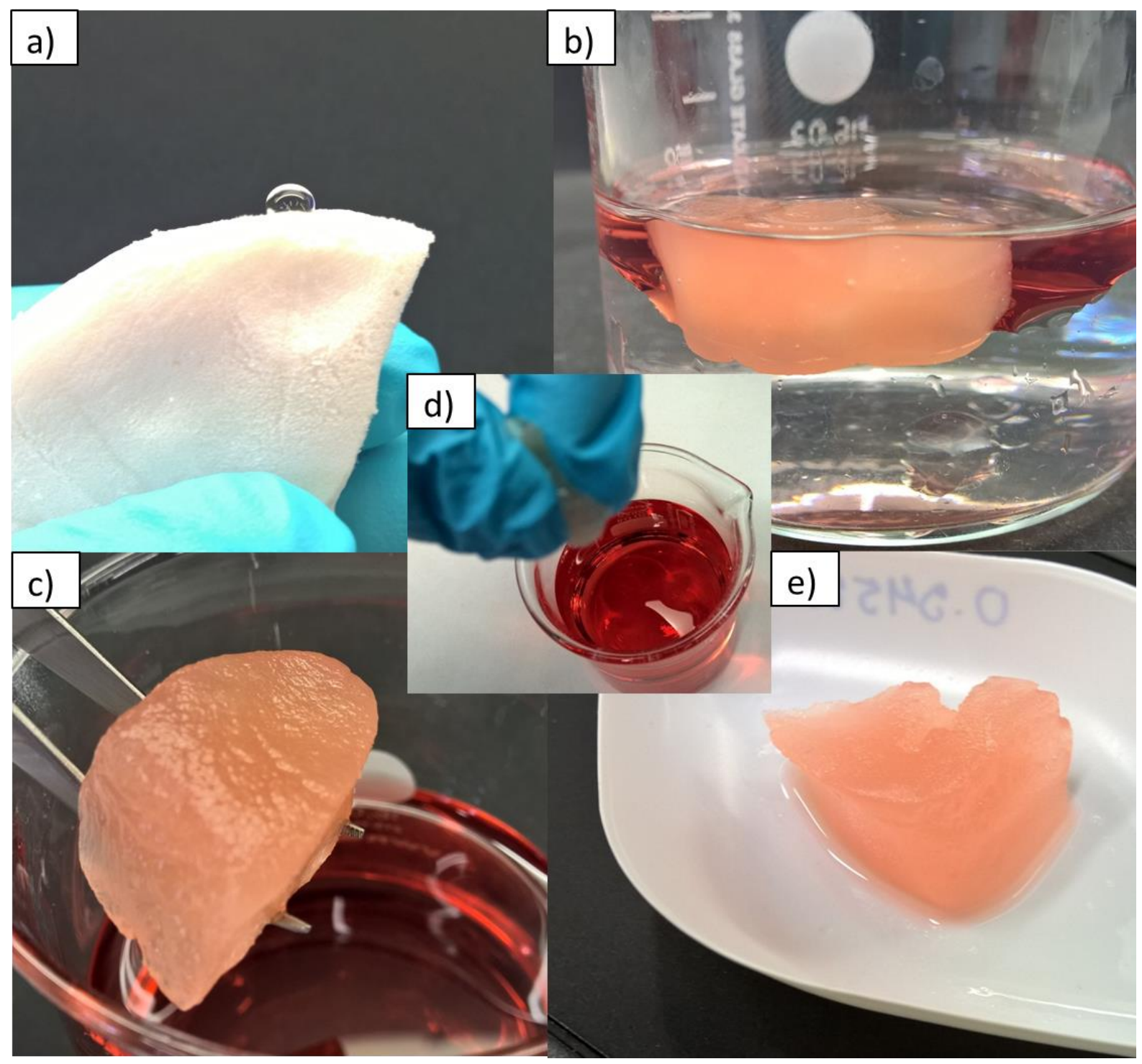

Fig. 9 High oil recovering efficiency and absorbent reusability of the hydrophobic DES_MCB (0.5) sponge. (a) hydrophobic cellulose aerogel, (b-c) absorbing marine diesel oil, (d) squeezing absorbed oil, and (e) aerogel after 30 cycles of mechanical squeezing and reabsorption of marine diesel oil.

All DES CNF sponges could be reused, and the absorbed oil could be recovered by simple mechanical squeezing. Fig. 10 shows the sponges' oil absorption capacities remaining after 30 squeezing-and-absorbing cycles. The oil absorption capacities of hydrophobic DES_Cel and DES_Flu sponges decreased by about $20 \mathrm{~g} / \mathrm{g}$, indicating their high reusability. Although the absorption capacities of the DES_Boa and DES_MCB sponges decreased to about $26 \mathrm{~g} / \mathrm{g}$, they retained more than two-thirds of their absorption capacities after 30 squeezing-and-absorption cycles. This performance has significant implications for various practical applications. 


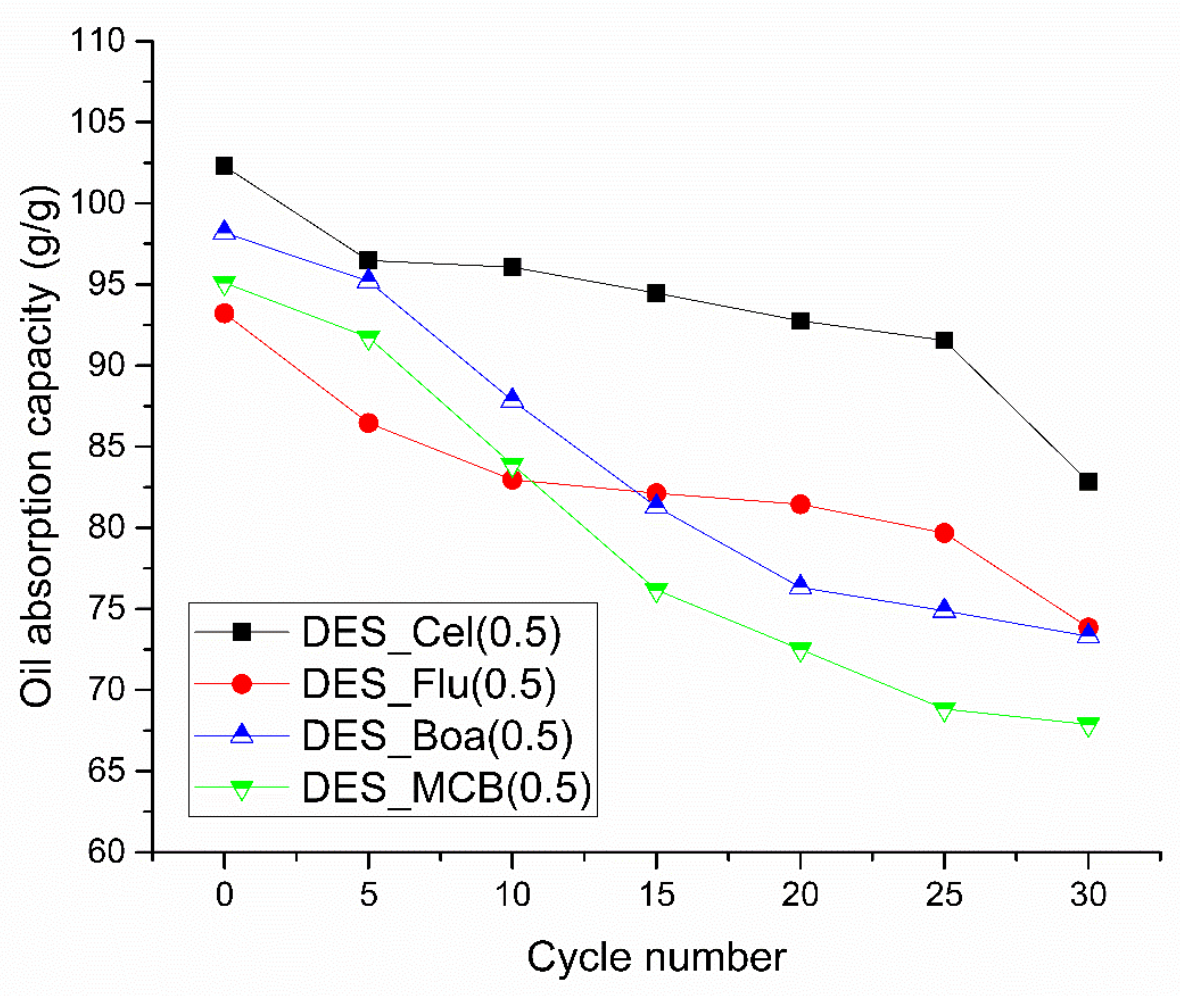

Fig. 10 Reusability of hydrophobic CNF sponges to absorb marine diesel oil.

Compared with other methods of recovering or reusing absorbents, including distillation (heating) [57], rinsing (solvent extraction) [8, 58], combustion (burning) [59], and vacuum filtration [60], squeezing is probably the simplest and most sustainable in terms of its use of energy, materials, and chemicals. Many of the other methods of recovering oil and reusing absorbents, including distillation, solvent extraction, and burning, are complicated, time consuming, inefficient, and energy intensive. Carbon-fiber aerogels made from raw cotton [61] and waste pulp [62] have previously been mechanically squeezed to recover oil and then reused, but their absorption capacity decreased dramatically in the second cycle, dropping to less than $55 \%$ of their original capacity. Therefore, mechanical squeezing could not be meaningfully applied to carbon absorbents in order to recover oil and reuse materials. Here, more than $70 \%$ of the absorbed diesel oil was efficiently recovered by facile, mechanical squeezing without the addition of other methods. Furthermore, the sponges could be reused for at least 30 cycles and maintained very high absorption capacities without sustaining significant structural damage. Oil absorbents with both ultra-high absorption capacity and high efficiency in terms of their oil recovery and sorbent reusability are highly desired. Therefore, CNF sponges derived from 
waste cellulose using a green DES treatment proves to be promising for the cleaning of oil and chemical spills.

\subsection{Comparison of various absorbents}

Some of recently developed absorbents and their absorption capacities for various oils and organic solvents are listed in Table 5. Among them, carbon absorbents-either from carbon blocks, such as carbon nanotubes (CNTs) [63] and graphene [64-67], or directly from carbonized materials, such as cotton fibers [61], cellulose fibers [62], and nanobacterial fibers [68], represent novel superabsorbents, demonstrating ultra-high absorption capacities. Absorbents made from nanocellulose hydrogels exhibited low density and high absorption capacity for various oils and organic solvents (up to $200 \mathrm{~g} / \mathrm{g}$ ), arising from the good dispersion and stable suspension of CNF or CNC $[8,14,69,70]$. The absorption capacity of nanocellulose fiber-based absorbents was slightly lower than that of carbon materials, but was considerably higher than that of other sorbents obtained from synthetic polymers $(14-84 \mathrm{~g} / \mathrm{g})[71,72]$.

Table 5. Comparison of various superabsorbents developed recently.

\begin{tabular}{|c|c|c|c|c|c|}
\hline Year & Reference & $\begin{array}{c}\text { Cost } \\
\text { estimation }\end{array}$ & Absorbent & $\begin{array}{c}\text { Oil recovery } \\
\text { method }\end{array}$ & $\begin{array}{c}\text { Absorption } \\
\text { capacity }(\mathrm{g} / \mathrm{g})\end{array}$ \\
\hline 2012 & {$[63]$} & ++ & B-doped CNT sponge & Burning & $25-125$ \\
\hline 2012 & [64] & ++ & $\begin{array}{c}\mathrm{N} \text {-doped graphene } \\
\text { framework }\end{array}$ & Burning & $200-600$ \\
\hline 2012 & [65] & ++ & Graphene sponge & Burning & $60-160$ \\
\hline 2012 & {$[66]$} & ++ & Spongy graphene & Distillation & $20-86$ \\
\hline 2013 & [67] & ++ & RGO foam & Burning & $70-122$ \\
\hline 2013 & [61] & + & $\begin{array}{l}\text { Carbon fiber aerogel } \\
\text { from raw cotton }\end{array}$ & $\begin{array}{l}\text { Burning or } \\
\text { distillation }\end{array}$ & $50-192$ \\
\hline 2013 & [62] & + & $\begin{array}{l}\text { Carbon microbelt } \\
\text { aerogel from pulp }\end{array}$ & Distillation & $56-188$ \\
\hline 2013 & [68] & ++ & $\begin{array}{l}\text { Carbon nanofiber } \\
\text { aerogels from BC }\end{array}$ & Burning & $106-312$ \\
\hline 2014 & [8] & + & $\begin{array}{l}\text { Silylated nanocellulose } \\
\text { sponge }\end{array}$ & $\begin{array}{c}\text { Solvent } \\
\text { extraction }\end{array}$ & $49-102$ \\
\hline 2014 & [14] & ++ & $\begin{array}{c}\text { Silane-modified } \\
\text { nanocellulose aerogel }\end{array}$ & Distillation & $139-356$ \\
\hline 2014 & [69] & ++ & $\begin{array}{c}\text { PVA/cellulose } \\
\text { nanofibril aerogel }\end{array}$ & - & $44-96$ \\
\hline 2014 & [57] & + & $\begin{array}{c}\text { Carbon aerogel from } \\
\text { winter melon }\end{array}$ & Distillation & $16-50$ \\
\hline 2013 & [71] & ++ & Poly(ODA-co-BA) & $\begin{array}{c}\text { Solvent } \\
\text { extraction }\end{array}$ & $14-84$ \\
\hline 2014 & [72] & + & PVF sponge & Squeezing & $14-57$ \\
\hline 2013 & [73] & - & Kapok fiber sponge & Squeezing & $44-85$ \\
\hline 2014 & [60] & - & Cotton & $\begin{array}{l}\text { Vacuum } \\
\text { filtration }\end{array}$ & $20-50$ \\
\hline 2016 & [12] & + & CNF aerogel & Evaporation & $28-47$ \\
\hline 2017 & [70] & + & Acetylated CNC & - & $100-200$ \\
\hline
\end{tabular}




\begin{tabular}{|c|c|c|c|c|c|}
\hline- & $\begin{array}{c}\text { Present } \\
\text { work }\end{array}$ & - & CNF aerogel & Squeezing & 65-205 \\
\hline
\end{tabular}

In the present work, the marine diesel oil absorption capacity of the hydrophobic CNF aerogel prepared from CNF hydrogels was ultra high (88-143 g/g), and for chloroform it was up to 205 $\mathrm{g} / \mathrm{g}$, which was much higher than that of cellulose fiber-based absorbents, and was even comparable to that of most carbon absorbents (as listed in Table 5). Similar absorption capacities as found in the present research have been achieved using carbon nanotubes and graphenes [64-66], but the cost of carbon nanotubes could be as high as 100 000-600 $000 € /$ t, and price of graphenes can be even higher. Furthermore, this research has demonstrated that absorbed marine diesel oil could be recovered in a fast and straightforward manner through simple mechanical squeezing, and that the hydrophobic CNF sponge could be reused extensively without requiring any other post-treatment. The oil recovery method, absorbent recyclability, and costs were preferable to those of most of carbon-based absorbents. Therefore, as an ultralight, cost-effective, and highly recyclable superabsorbent, the hydrophobic CNF sponge has been demonstrated to be a possible alternative to carbon-based absorbents for the removal of spilled oil and organic pollutants from marine environments.

\section{Conclusion}

The chapter describes basic principle of the manufacturing CNF hydrogels, which can be further processed into hydrophobic cellulose aerogels. Nanofibrillation, silylation, and freeze-drying are combined to create a porous, hydrophobic, superabsorbent CNF sponges. Utilization of renewable resources, low cost raw materials and simple and environmentally friendly manufacturing process make these superabsorbents possible alternative for cleaning oil and chemical spills.

\section{References}

1. Klemm D, Kramer F, Moritz S, Tom Lindström T, Ankerfors M, Gray D, Dorris A (2011) Nanocelluloses: A New Family of Nature-Based Materials. Angew Chem Int Ed 50:54385466. doi: 10.1002/anie.201001273

2. Siró I, Plackett D (2010) Microfibrillated cellulose and new nanocomposite materials: a review. Cellulose 17:459-494. doi: 10.1007/s10570-010-9405-y

3. Herrick FW, Casebier RL, Hamilton JK, Sandberg KRJ (1983) Microfibrillated cellulose: Morphology and accessibility. J Appl Polym Sci Appl Polym Symp 37:815-827. 
4. Sirviö JA, Visanko M, Liimatainen H (2015) Deep eutectic solvent system based on choline chloride-urea as a pre-treatment for nanofibrillation of wood cellulose. Green Chem 17:3401-3406. doi: 10.1039/C5GC00398A

5. Singh BS, Lobo HR, Shankarling GS (2012) Choline chloride based eutectic solvents: Magical catalytic system for carbon-carbon bond formation in the rapid synthesis of $\beta$ hydroxy functionalized derivatives. Catal Commun 24:70-74. doi: 10.1016/j.catcom.2012.03.021

6. Liu H, Geng B, Chen Y, Wang H (2017) Review on the Aerogel-Type Oil Sorbents Derived from Nanocellulose. ACS Sustain Chem Eng 5:49-66. doi: 10.1021/acssuschemeng.6b02301

7. Zanini M, Lavoratti A, Lazzari LK, Galiotto D, Pagnocelli M, Baldasso C, Zattera AJ (2016) Producing aerogels from silanized cellulose nanofiber suspension. Cellulose 24:769-779. doi: 10.1007/s10570-016-1142-4

8. Zhang Z, Sèbe G, Rentsch D, Zimmermann T, Tingaut P (2014) Ultralightweight and Flexible Silylated Nanocellulose Sponges for the Selective Removal of Oil from Water. Chem Mater 26:2659-2668. doi: 10.1021/cm5004164

9. Korhonen JT, Kettunen M, Ras RHA, Ikkala O (2011) Hydrophobic Nanocellulose Aerogels as Floating, Sustainable, Reusable, and Recyclable Oil Absorbents. ACS Appl Mater Interfaces 3:1813-1816. doi: 10.1021/am200475b

10. Cervin NT, Aulin C, Larsson PT, Wågberg L (2012) Ultra porous nanocellulose aerogels as separation medium for mixtures of oil/water liquids. Cellulose 19:401-410. doi: 10.1007/s10570-011-9629-5

11. Zhou S, Liu P, Wang M, Zhao H, Yang J, Xu F (2016) Sustainable, Reusable, and Superhydrophobic Aerogels from Microfibrillated Cellulose for Highly Effective Oil/Water Separation. ACS Sustain Chem Eng. 4:6409-6416 doi: 10.1021/acssuschemeng.6b01075

12. Mulyadi A, Zhang Z, Deng Y (2016) Fluorine-Free Oil Absorbents Made from Cellulose Nanofibril Aerogels. ACS Appl Mater Interfaces 8:2732-2740. doi: 10.1021/acsami.5b10985

13. Wang Y, Yadav S, Heinlein T, Konjik V, Breitzke H, Buntkowsky G, Schneider JJ, Zhang $\mathrm{K}$ (2014) Ultra-light nanocomposite aerogels of bacterial cellulose and reduced graphene oxide for specific absorption and separation of organic liquids. RSC Adv 4:21553-21558. doi: $10.1039 / \mathrm{c} 4 \mathrm{ra} 02168 \mathrm{a}$

14. Jiang F, Hsieh Y-L (2014) Amphiphilic superabsorbent cellulose nanofibril aerogels. J Mater Chem A 2:6337-6342. doi: 10.1039/c4ta00743c

15. Sai H, Xing L, Xiang J, Cui L, Jiao J, Zhao C, Lia Z, Li F (2013) Flexible aerogels based on an interpenetrating network of bacterial cellulose and silica by a non-supercritical drying process. J Mater Chem A 1:7963-7970. doi: 10.1039/c3ta11198a

16. Gupta S, Tai N-H (2016) Carbon materials as oil sorbents: a review on the synthesis and performance. J Mater Chem A 4:1550-1565. doi: 10.1039/C5TA08321D 
17. Sabir S (2015) Approach of Cost-Effective Adsorbents for Oil Removal from Oily Water. Crit Rev Environ Sci Technol 45:1916-1945. doi: 10.1080/10643389.2014.1001143

18. Syed S, Alhazzaa MI, Asif M (2011) Treatment of oily water using hydrophobic nanosilica. Chem Eng J 167:99-103. doi: 10.1016/j.cej.2010.12.006

19. Santander M, Rodrigues RT, Rubio J (2011) Modified jet flotation in oil (petroleum) emulsion/water separations. Colloids Surf Physicochem Eng Asp 375:237-244. doi: 10.1016/j.colsurfa.2010.12.027

20. Feng J, Nguyen ST, Fan Z, Duong HM (2015) Advanced fabrication and oil absorption properties of super-hydrophobic recycled cellulose aerogels. Chem Eng J 270:168-175. doi: 10.1016/j.cej.2015.02.034

21. Yang S, Chen L, Mu L, Hao B, Ma P-C (2015) Low cost carbon fiber aerogel derived from bamboo for the adsorption of oils and organic solvents with excellent performances. RSC Adv 5:38470-38478. doi: 10.1039/C5RA03701H

22. Cortez JSA, Kharisov BI, Quezada TES, García TCH (2017) Micro- and nanoporous materials capable of absorbing solvents and oils reversibly: the state of the art. Pet Sci 14:84-104. doi: 10.1007/s12182-016-0143-0

23. Al-Majed AA, Adebayo AR, Hossain ME (2012) A sustainable approach to controlling oil spills. J Environ Manage 113:213-227. doi: 10.1016/j.jenvman.2012.07.034

24. Banerjee SS, Joshi MV, Jayaram RV (2006) Treatment of oil spills using organo-fly ash. Desalination 195:32-39. doi: 10.1016/j.desal.2005.10.038

25. Rajaković-Ognjanović V, Aleksić G, Rajaković L (2008) Governing factors for motor oil removal from water with different sorption materials. J Hazard Mater 154:558-563. doi: 10.1016/j.jhazmat.2007.10.066

26. Toyoda M, Aizawa J, Inagaki M (1998) Sorption and recovery of heavy oil by using exfoliated graphite. Desalination 115:199-201.

27. Okiel K, El-Sayed M, El-Kady MY (2011) Treatment of oil-water emulsions by adsorption onto activated carbon, bentonite and deposited carbon. Egypt J Pet 20:9-15. doi: 10.1016/j.ejpe.2011.06.002

28. Carmody O, Frost R, Xi Y, Kokot S (2007) Adsorption of hydrocarbons on organo-claysImplications for oil spill remediation. J Colloid Interface Sci 305:17-24. doi: 10.1016/j.jcis.2006.09.032

29. Cho YK, Park EJ, Kim YD (2014) Removal of oil by gelation using hydrophobic silica nanoparticles. J Ind Eng Chem 20:1231-1235. doi: 10.1016/j.jiec.2013.08.005

30. Wang D, McLaughlin E, Pfeffer R, Lin YS (2012) Adsorption of oils from pure liquid and oil-water emulsion on hydrophobic silica aerogels. Sep Purif Technol 99:28-35. doi: 10.1016/j.seppur.2012.08.001 
31. Lin C, Hong Y-J, Hu AH (2010) Using a composite material containing waste tire powder and polypropylene fiber cut end to recover spilled oil. Waste Manag 30:263-267. doi: 10.1016/j.wasman.2009.03.001

32. Oh Y-S, Maeng J, Kim S-J (2000) Use of microorganism-immobilized polyurethane foams to absorb and degrade oil on water surface. Appl Microbiol Biotechnol 54:418-423.

33. Wei QF, Mather RR, Fotheringham AF, Yang RD (2003) Evaluation of nonwoven polypropylene oil sorbents in marine oil-spill recovery. Mar Pollut Bull 46:780-783. doi: 10.1016/S0025-326X(03)00042-0

34. Teas C, Kalligeros S, Zanikos F, Stournas S, Lois E, Anastopoulos G (2001) Investigation of the effectiveness of absorbent materials in oil spills clean up. Desalination 140:259-264.

35. Toyoda M, Inagaki M (2003) Sorption and Recovery of Heavy Oils by Using Exfoliated Graphite. Spill Sci Technol Bull 8:467-474. doi: 10.1016/S1353-2561(03)00131-2

36. Wang J, Zheng Y, Wang A (2012) Effect of kapok fiber treated with various solvents on oil absorbency. Ind Crops Prod 40:178-184. doi: 10.1016/j.indcrop.2012.03.002

37. Ali N, El-Harbawi M, Jabal AA, Yin C-Y (2012) Characteristics and oil sorption effectiveness of kapok fibre, sugarcane bagasse and rice husks: oil removal suitability matrix. Environ Technol 33:481-486. doi: 10.1080/09593330.2011.579185

38. Hussein M, Amer AA, Sawsan II (2011) Heavy oil spill cleanup using law grade raw cotton fibers: trial for practical application. J Pet Technol Altern Fuels 2:132-140.

39. Sun X-F, Sun, Sun J-X (2002) Acetylation of Rice Straw with or without Catalysts and Its Characterization as a Natural Sorbent in Oil Spill Cleanup. J Agric Food Chem 50:64286433. doi: 10.1021/jf020392o

40. Khan E, Virojnagud W, Ratpukdi T (2004) Use of biomass sorbents for oil removal from gas station runoff. Chemosphere 57:681-689. doi: 10.1016/j.chemosphere.2004.06.028

41. Annunciado TR, Sydenstricker THD, Amico SC (2005) Experimental investigation of various vegetable fibers as sorbent materials for oil spills. Mar Pollut Bull 50:1340-1346. doi: 10.1016/j.marpolbul.2005.04.043

42. Wahi R, Chuah LA, Choong TSY, Ngaini Z, Nourouzi MM (2013) Oil removal from aqueous state by natural fibrous sorbent: An overview. Sep Purif Technol 113:51-63. doi: 10.1016/j.seppur.2013.04.015

43. Nourbakhsh A, Ashori A (2010) Particleboard made from waste paper treated with maleic anhydride. Waste Manag Res 28:51-55. doi: 10.1177/0734242X09336463

44. Segal L, Creely JJ, Martin AE, Conrad CM (1959) An empirical method for estimating the degree of crystallinity of native cellulose using the X-ray diffractometer. Text Res J 29:786-794.

45. Xie Y, Hill CAS, Xiao Z, Militz H, Mai C (2010) Silane coupling agents used for natural fiber/polymer composites: A review. Compos Part Appl Sci Manuf 41:806-819. doi: 10.1016/j.compositesa.2010.03.005 
46. Li P, Sirviö JA, Haapala A, Liimatainen H (2017) Cellulose Nanofibrils from Nonderivatizing Urea-Based Deep Eutectic Solvent Pretreatments. ACS Appl Mater Interfaces 9:2846-2855. doi: 10.1021/acsami.6b13625

47. Sharma M, Mukesh C, Mondal D, Prasad K (2013) Dissolution of $\alpha$-chitin in deep eutectic solvents. RSC Adv 3:18149. doi: 10.1039/c3ra43404d

48. Abbott AP, Bell TJ, Handa S, Stoddart B (2005) O-Acetylation of cellulose and monosaccharides using a zinc based ionic liquid. Green Chem 7:705. doi: 10.1039/b511691k

49. Zhang Q, Benoit M, De Oliveira Vigier K, Barrault J, Francois J (2012) Green and Inexpensive Choline-Derived Solvents for Cellulose Decrystallization. Chem - Eur J 18:1043-1046. doi: 10.1002/chem.201103271

50. Du C, Zhao B, Chen X-B, Birbilis N, Yang H (2016) Effect of water presence on choline chloride-2urea ionic liquid and coating platings from the hydrated ionic liquid. Sci Rep. 6:29225. doi: 10.1038/srep29225

51. Besbes I, Alila S, Boufi S (2011) Nanofibrillated cellulose from TEMPO-oxidized eucalyptus fibres: Effect of the carboxyl content. Carbohydr Polym 84:975-983. doi: 10.1016/j.carbpol.2010.12.052

52. Lasseuguette E, Roux D, Nishiyama Y (2008) Rheological properties of microfibrillar suspension of TEMPO-oxidized pulp. Cellulose 15:425-433. doi: 10.1007/s10570-0079184-2

53. Iotti M, Gregersen $\varnothing \mathrm{W}$, Moe S, Lenes M (2011) Rheological Studies of Microfibrillar Cellulose Water Dispersions. J Polym Environ 19:137-145. doi: 10.1007/s10924-0100248-2

54. Mohtaschemi M, Sorvari A, Puisto A, Nuopponen M, Seppälä J, Alava MJ (2014) The vane method and kinetic modeling: shear rheology of nanofibrillated cellulose suspensions. Cellulose 21:3913-3925. doi: 10.1007/s10570-014-0409-x

55. Zhang Z, Tingaut P, Rentsch D, Zimmermann T, Sebe G (2015) Controlled Silylation of Nanofibrillated Cellulose in Water: Reinforcement of a Model Polydimethylsiloxane Network. ChemSusChem 8:2681-2690. doi: 10.1002/cssc.201500525

56. Materne T, de Buyl F, Witucki G (2004) Organosilane Technology in Coating Applications: Review and Perspectives. http://www4.dowcorning.com/content/publishedlit/26-140201.pdf. Accessed 27 February 2017

57. Li Y-Q, Samad YA, Polychronopoulou K, Alhassan SM, Liao K (2014) Carbon Aerogel from Winter Melon for Highly Efficient and Recyclable Oils and Organic Solvents Absorption. ACS Sustain Chem Eng 2:1492-1497. doi: 10.1021/sc500161b

58. Sai H, Fu R, Xing L, Xiang J, Li Z, Li F, Zhang T (2015) Surface Modification of Bacterial Cellulose Aerogels' Web-like Skeleton for Oil/Water Separation. ACS Appl Mater Interfaces 7:7373-7381. doi: 10.1021/acsami.5b00846 
59. Zhao J, Ren W, Cheng H-M (2012) Graphene sponge for efficient and repeatable adsorption and desorption of water contaminations. J Mater Chem 22:20197-20202. doi: $10.1039 / \mathrm{c} 2 \mathrm{jm} 34128 \mathrm{j}$

60. Liu F, Ma M, Zang D, Gao Z, Wang C (2014) Fabrication of superhydrophobic/superoleophilic cotton for application in the field of water/oil separation. Carbohydr Polym 103:480-487. doi: 10.1016/j.carbpol.2013.12.022

61. Bi H, Yin Z, Cao X, Xie X, Tan C, Huang X, Chen B, Chen F, Yang Q, Bu X, Lu X, Sun L, Zhang H (2013) Carbon Fiber Aerogel Made from Raw Cotton: A Novel, Efficient and Recyclable Sorbent for Oils and Organic Solvents. Adv Mater 25:5916-5921. doi: 10.1002/adma.201302435

62. Bi H, Huang X, Wu X, Cao X, Tan C, Yin Z, Lu X, Sun L, Zhang H (2014) Carbon Microbelt Aerogel Prepared by Waste Paper: An Efficient and Recyclable Sorbent for Oils and Organic Solvents. Small 10:3544-3550. doi: 10.1002/smll.201303413

63. Hashim DP, Narayanan NT, Romo-Herrera JM, Cullen DA, Hahm MG, Lezzi P, Suttle JR, Kelkhoff D, Munoz-Sandoval E, Ganguli S, Roy AK, Smith DJ, Vajtai R, Sumpter BG, Meunier V, Terrones H, Terrones M, Ajayan PM (2012) Covalently bonded threedimensional carbon nanotube solids via boron induced nanojunctions. Sci Rep 2:1-8. doi: 10.1038/srep00363

64. Zhao Y, Hu C, Hu Y, Cheng H, Shi G, Liangti Q (2012) A Versatile, ultralight, nitrogendoped Graphene Framework. Angew Chem Int Ed 51:11371-11375. doi: 10.1002/anie.201206554

65. Zhao J, Ren W, Cheng H-M (2012) Graphene sponge for efficient and repeatable adsorption and desorption of water contaminations. J Mater Chem 22:20197. doi: 10.1039/c2jm34128j

66. Bi H, Xie X, Yin K, Zhou Y, Wan S, He L, Xu F, Banhart F, Sun L, Ruoff RS (2012) Spongy Graphene as a Highly Efficient and Recyclable Sorbent for Oils and Organic Solvents. Adv Funct Mater 22:4421-4425. doi: 10.1002/adfm.201200888

67. He Y, Liu Y, Wu T, Ma J, Wang X, Gong Q, Kong W, Xing F, Liu Y, Gao J (2013) An environmentally friendly method for the fabrication of reduced graphene oxide foam with a super oil absorption capacity. J Hazard Mater 260:796-805. doi: 10.1016/j.jhazmat.2013.06.042

68. Wu Z-Y, Li C, Liang H-W, Chen J-F, Yu S-H (2013) Ultralight, Flexible, and FireResistant Carbon Nanofiber Aerogels from Bacterial Cellulose. Angew Chem 125:29973001. doi: 10.1002/ange. 201209676

69. Zheng Q, Cai Z, Gong S (2014) Green synthesis of polyvinyl alcohol (PVA)-cellulose nanofibril (CNF) hybrid aerogels and their use as superabsorbents. J Mater Chem A 2:3110-3118. doi: 10.1039/c3ta14642a

70. Abraham E, Weber DE, Sharon S, Lapidot S, Shoseyov O (2017) Multifunctional Cellulosic Scaffolds from Modified Cellulose Nanocrystals. ACS Appl Mater Interfaces 9:2010-2015. doi: 10.1021/acsami.6b13528 
71. Song C, Ding L, Yao F, Deng J, Yang W (2013) $\beta$-Cyclodextrin-based oil-absorbent microspheres: Preparation and high oil absorbency. Carbohydr Polym 91:217-223. doi: 10.1016/j.carbpol.2012.08.036

72. Pan Y, Shi K, Peng C, Wang W, Liu Z, Ji X (2014) Evaluation of Hydrophobic PolyvinylAlcohol Formaldehyde Sponges As Absorbents for Oil Spill. ACS Appl Mater Interfaces 6:8651-8659. doi: 10.1021/am5014634

73. Wang J, Wang A (2013) Acetylated modification of kapok fiber and application for oil absorption. Fibers Polym 14:1834-1840. doi: 10.1007/s12221-013-1834-4 